\title{
REVIEW ARTICLE OPEN Cybermaterials: materials by design and accelerated insertion of materials
}

\author{
Wei Xiong ${ }^{1}$ and Gregory B Olson ${ }^{1,2}$
}

Cybermaterials innovation entails an integration of Materials by Design and accelerated insertion of materials (AIM), which transfers studio ideation into industrial manufacturing. By assembling a hierarchical architecture of integrated computational materials design (ICMD) based on materials genomic fundamental databases, the ICMD mechanistic design models accelerate innovation. We here review progress in the development of linkage models of the process-structure-property-performance paradigm, as well as related design accelerating tools. Extending the materials development capability based on phase-level structural control requires more fundamental investment at the level of the Materials Genome, with focus on improving applicable parametric design models and constructing high-quality databases. Future opportunities in materials genomic research serving both Materials by Design and AIM are addressed.

npj Computational Materials (2016) 2, 15009; doi:10.1038/npjcompumats.2015.9; published online 12 February 2016

\section{BACKGROUND: ICMD BLUEPRINT}

The far-reaching multi-agency enterprise, Materials Genome Initiative (MGI), ${ }^{1,2}$ highlights computational materials design techniques grounded in fundamental databases, which can support an ambition of decreasing the full development cycle of new materials from the present $10-20$ years to $\leqslant 5$ years. As a subfield of the broader field of integrated computational materials engineering (ICME), which includes modelling of existing materials, ${ }^{3,4}$ the MGl centres on design of new materials and their accelerated qualification through the inherent predictability of designed systems. Creation of the infrastructure of this technology has been a global activity as summarised in a recent series of viewpoint papers on materials genomics. ${ }^{5-10}$ Particularly notable has been the design work of Bhadeshia $^{8}$ at the University of Cambridge and his former students including Harada ${ }^{11,12}$ and Reed. ${ }^{13}$ The highest achievements of full cycle compression have been demonstrated in US research, which will be the focus of this paper.

In the development of applied engineering materials design powered by fundamental thermodynamic and kinetic genomic databases, a hierarchical infrastructure called ICMD presents a proven scenario of materials genomic design for accelerated engineering innovation. As indicated in Figure 1, the backbone of the ICMD infrastructure is composed of Materials by Design and accelerated insertion of materials (AIM) techniques. The application of both techniques spans the entire course of materials innovation, which can be divided into three phases: concept implementation, materials and processing design, and material qualification. The quality of the materials innovation is determined by the mechanistic models applied in the ICMD framework, which follow the universal process-structure-property-performance paradigm in materials science. ${ }^{14}$ In Materials by Design, both process-structure and structure-property models are evaluated and refined to maximise the model-predictability grounded in the Materials Genome, which is powered by fundamental research on high-quality databases. Although the AIM technique also takes mechanistic models as its basis, it requires extra effort in uncertainty quantification, design sensitivity analysis, integrated component-level process simulation and probabilistic prediction of manufacturing variation.

A recent review of ICMD application highlights notable achievements made in ferrous materials. ${ }^{15}$ This review provides further detail on the linkage models for Materials by Design, and methods of qualification adopted in AIM for a technology transfer from lab-scale materials innovation to industrial commercial practice. It is formulated as a snapshot of materials innovations on selected alloy designs for improving mechanical performance. Its foundation is sufficiently general that all levels of materials design should share the same principles, not only for metal and alloys, but also for oxides and polymers. ${ }^{14,16,17}$

Here we revisit some key process-structure and structureproperty linkage models applied in Materials by Design followed by a technical review of the AIM method application in projects supported by DARPA (Defense Advanced Research Projects Agency) and National Aeronautics and Space Administration. Although the above linkage models are applied in AIM technology as well, related discussion on AIM will be more about its unique efforts on model integration, uncertainty quantification and design sensitivity control. Future research opportunities and perspectives are presented as concluding remarks in the last section.

\section{MATERIALS BY DESIGN: DESIGN ENGINE}

The paradigm of materials design guided by governing processing-structure-properties-performance is a universal principle for developing advanced materials. ${ }^{14}$ Predictive-science-based computational modelling reinforced by experimental calibration allows us to perform multiscale modelling for various properties with temperature/time dependence. Therefore, the development

\footnotetext{
${ }^{1}$ Department of Materials Science and Engineering, Northwestern University, Evanston, IL, USA and ${ }^{2}$ QuesTek Innovations LLC, Evanston, IL, USA.

Correspondence: W Xiong (wxiong@yahoo.com)

Received 17 August 2015; revised 27 October 2015; accepted 27 October 2015 


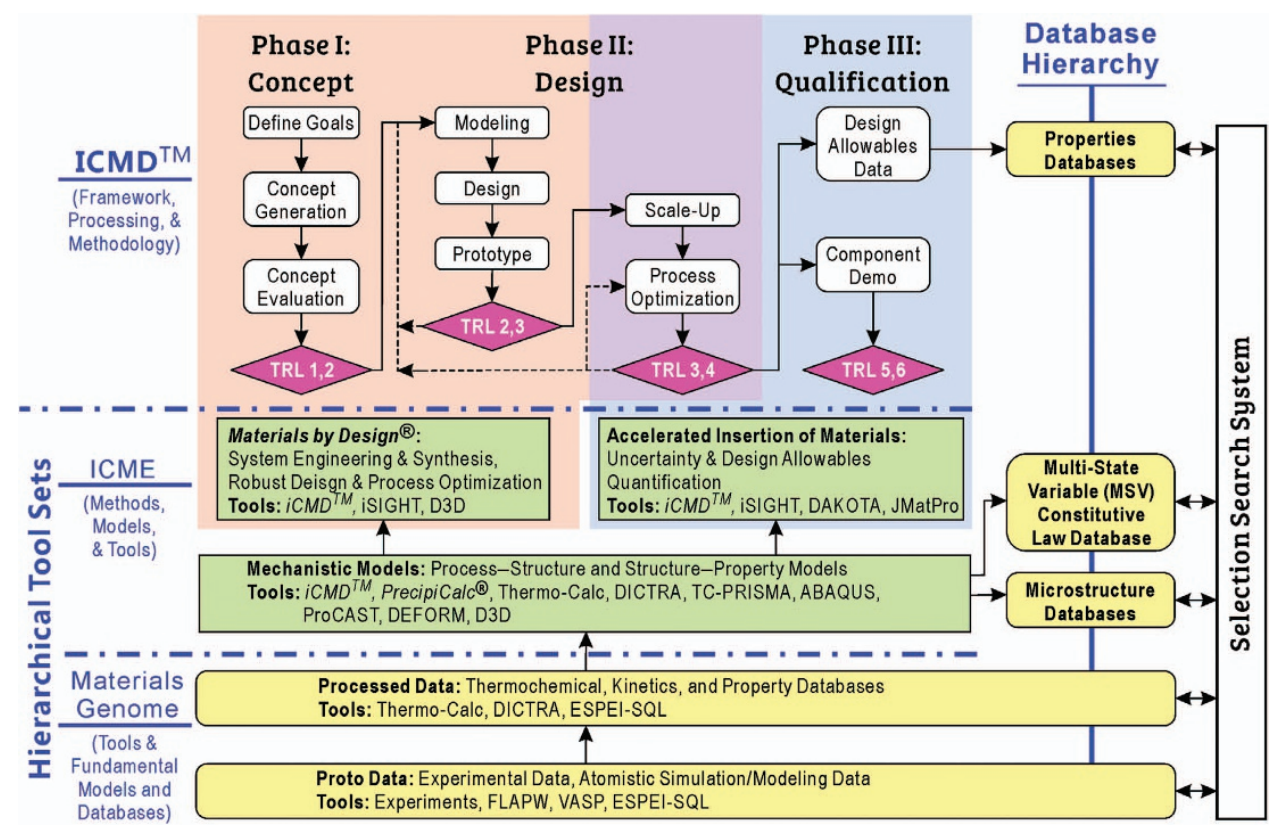

Figure 1. Overall hierarchical architecture of ICMD methods, tools and techniques are highlighted in green and databases are marked in yellow. Please note that iCMD is the toolkit used during application of ICME methods based on Materials Genome. Figure is reprinted with permission from Elsevier.

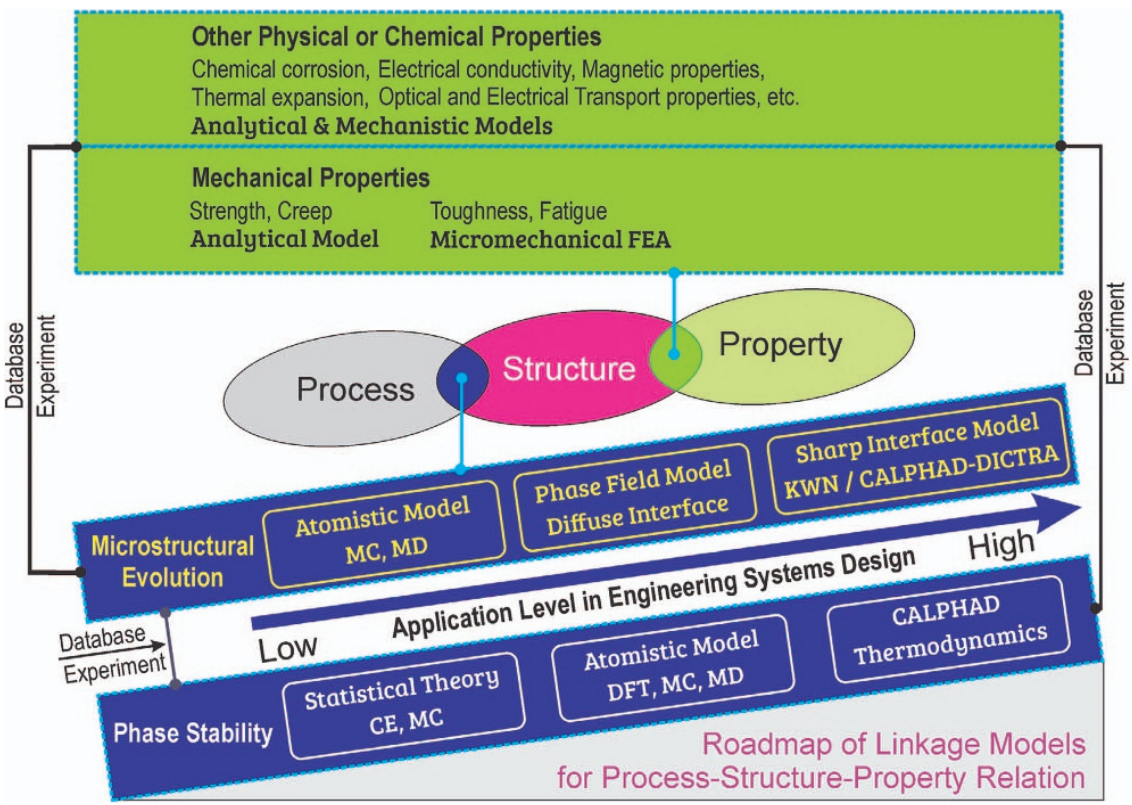

Figure 2. Materials design roadmap for linkage models of process-structure and structure-property relations. CE, cluster expansion; MC, Monte Carlo; MD, molecular dynamics.

of the process-structure and structure-property models will be beneficial to Materials by Design, and boost AIM applications.

As shown in Figure 2, process-structure models empower two levels of modelling: phase stability and microstructural evolution, which establish a fundamental basis for structure-property design models. With particular engineering design purpose, high-quality engineering models are integrated with science-based mechanistic models forming a hierarchical model system.

Process-structure relation and design models

In the course of systems design for advanced materials, a thorough understanding of thermodynamics and kinetics enables processing design, which often starts with a parametric design for chemical composition. As shown in Figure 3, intrinsic design parameters for materials processing encompass chemical composition, temperature, pressure and external force fields, on which even a small adjustment may lead to significantly different evolution of microstructure driven by the thermodynamics and kinetics of the system. The CALPHAD (calculation of phase diagrams) method ${ }^{18}$ and its correlated modelling techniques quantitatively express our mechanistic understanding of the process-structure linkage relations.

Thermodynamics is the core of the precipitation simulation. Considerable efforts have been made on integration of density functional theory (DFT)-based atomistic modelling, CALPHAD and 
Intrinsic Design Factors of Materials by Design (

\begin{tabular}{|c|c|c|c|}
\hline Processing & Stru & dcture & Properties \\
\hline Composition & $\begin{array}{l}\text { Phases } \\
\text { diffusivity }\end{array}$ & transition temperature & Strength \\
\hline $\begin{array}{l}\text { Temperature } \\
\text { Time }\end{array}$ & $\begin{array}{l}\text { phase fraction } \\
\text { distribution } \\
\text { phase composition } \\
\text { lattice constant }\end{array}$ & $\begin{array}{l}\text { molar volume } \\
\text { elastic constants } \\
\text { hardness } \\
\text { etc. }\end{array}$ & $\begin{array}{l}\text { Toughness } \\
\text { Creep }\end{array}$ \\
\hline $\begin{array}{l}\text { Pressure } \\
\text { including external stress } \\
\text { and other field variables. }\end{array}$ & $\begin{array}{l}\text { Grains \& Particle } \\
\text { defects (dislocation, } \\
\text { diffusivity } \\
\text { size, distribution } \\
\text { interface property }\end{array}$ & $\begin{array}{l}\text { Dispersion } \\
\text { SF, twining...) } \\
\text { grain boundary } \\
\text { orientation } \\
\text { etc. }\end{array}$ & $\begin{array}{l}\text { Fatigue } \\
\ldots \ldots\end{array}$ \\
\hline
\end{tabular}

Figure 3. Intrinsic design factor of the process-structure-property-performance paradigm. The most common attributes of design factors for microstructure control are presented.

phase equilibrium measurements for assembling materials genomic databases. DFT calculations for zero-kelvin thermalchemical properties, such as, enthalpy of formation, are often used as protodata to support CALPHAD thermodynamic modelling. This is now considered as a routine method to perform physically sound thermodynamic modelling, which can sometimes circumvent the restriction of calorimetry (e.g., radiative alloy systems), ${ }^{19,20}$ and assist in determining reliable experimental data sets. $^{19,21-23}$ At present, there are many commercial software packages available based on the CALPHAD technique, e.g., Thermo-Calc, Pandat, FactSage, MTDATA. ${ }^{24,25}$ However, not until the release of the DICTRA (diffusion controlled transformations) package by the Thermo-Calc software company in early $90 \mathrm{~s}^{26,27}$ for diffusion kinetic modelling, did the CALPHAD approach start to demonstrate its capability of handling sophisticated processstructure modelling. The significance of the CALPHAD method nowadays has exceeded its original definition as phase diagram computation. It is indisputable that the modern CALPHAD approach $^{28}$ serves as a fundamental technique for establishing the materials genomic databases, and widely recognised as a foundational tool for Materials by Design.

When related CALPHAD genomic databases are available, although thermodynamic and diffusion calculations can be readily performed, one should be aware of application limits and evaluate the quality of database predictions prior to a pragmatic design, or before adopting CALPHAD as an input for explicit microstructural simulation. One should also bear in mind that a fundamental CALPHAD database generally provides the Gibbs energy of bulk phases by neglecting the contribution from interfaces to the total energy of the system. However, when modelling precipitation strengthening, the Gibbs-Thompson effects, i.e., size-dependent capillary effects, need to be considered. When experimental data determined by atom probe tomography (APT) is available, a semilog plot of composition versus inverse of particle size can often generate a good trajectory defining equilibrium tie-lines and initial critical nucleus size defining interfacial energy. ${ }^{29,30}$ In addition, elastic coherency (misfit) energy, $G_{\mathrm{el}}$, can be evaluated for a further energy penalty to the precipitation when particles are coherent. In the work by Olson et al. ${ }^{31}$ the method of estimating coherent interfacial energy $\left(G_{\text {coh }}\right)$ and elastic misfit energy was demonstrated using single sensor differential thermal analysis ${ }^{32}$ combined with APT.

Another issue related to phase stability should be addressed when applying CALPHAD thermodynamics is evaluation of competitive growth behaviour of different phases. As CALPHAD thermodynamic database calculates phase equilibrium as a default option, some phases with sluggish formation should be carefully evaluated in a quantitative comparison with experimental data determined from materials processing, which are generally nonequilibrium. For example, in the work performed by Wusatowska-Sarnek et al. $^{33}$ experimental phase fraction were initially compared with calculated results under full equilibrium. Good agreement was ultimately obtained when the calculation was performed using constrained equilibria, under which topologically close-packed phases are excluded because of their sluggish formation.

In view of the above, for the sake of parametric design, experimental validation is essential to assess the accuracy of a CALPHAD model-prediction. This can in turn contribute to database refinement in support of higher fidelity applications of Materials by Design and AIM methodologies. Similar to the case in thermodynamics, diffusional kinetic databases also require adjustments for the constrained case in a quantitative comparison with experimental results measured after specific processing. For developing dual microstructure processing turbine disk in a project supported by National Aeronautics and Space Administration Glenn Research Center, ${ }^{31}$ a multicomponent CALPHAD diffusion database was constructed by National Institute of Standards and Technology, which demonstrates a good predictability after calibration on the atomic mobility of $\mathrm{Nb}, \mathrm{Al}, \mathrm{Ti}$ and $\mathrm{Cr}$ in fcc using multicomponent diffusion couples made between disc alloys and pure $\mathrm{Ni}$. A need for calibration of CALPHAD diffusivity databases originates from the simplifications made by omitting the influence of fast diffusion path, e.g., dislocations, phase/grain boundaries. A diffusion scaling factor, $D_{\text {scale, }}$ can be applied to the diffusivity matrix for calibration, particularly for a precipitation simulation.

A well-calibrated CALPHAD thermodynamic and kinetic database is a prerequisite of accurate parametric control of microstructural length and time scales. For example, effective precipitation strengthening relies on the size control of the particle precipitation, and thus requires predictive models for the kinetic process of particle size evolution. A good example is the extensive application of the coarsening model represented by the Lifshitz-Slyozov-Wagner (LSW) theory ${ }^{34-38}$ for precipitation size evolution in a dilute binary system. To couple with the CALPHAD thermodynamic/kinetic databases for multicomponent and multiphase simulation, several models ${ }^{39,40}$ were proposed based on extensions of the LSW theory. One of the simplified models was proposed by Lee et $a l^{39}$ based on the dilute solution case. A later work performed by Umantsev and Olson ${ }^{40}$ removed the constraint of dilute solution thermodynamics, but neglected effects of capillarity on the precipitation composition. Further improvements have been made by Morral and Purdy ${ }^{36,37}$ with a more general description of the coarsening in multicomponent alloys. Kuehmann and Voorhees ${ }^{38}$ considered flux balance boundary conditions on the interface rather than local equilibrium, but off-diagonal terms in the diffusion matrix were omitted for 
simplification. For practical design purposes, it is found that the simplified dilute solution model proposed by Lee et al. $^{39}$ may be directly applied, if only an underdeveloped database is available. However, the Morral-Purdy model ${ }^{36,37}$ overall provides coarsening rate with highest accuracy.

To maximise hardening effects by reducing initial strengthening particle size, a designed alloy usually preserves a high-solute supersaturation, i.e., high-driving force for nucleation of a secondphase precipitate particle, which can allow a bypass of the growth regime from nucleation directly to the coarsening regime. Therefore, the coarsening rate predicted by the aforementioned multicomponent coarsening models is often adopted as the principle design factor to control overall precipitation rate. Such a concept can be confirmed using a more rigorous approach based on the Kampmann and Wagner numerical (KWN) model ${ }^{41}$ for concomitant nucleation, growth and coarsening of precipitates, extended to multicomponent alloy systems. A detailed discussion on the influence of supersaturation was made by Robson, ${ }^{42}$ who analysed different scenarios with overlapping of nucleation, growth and coarsening occurs during precipitation. Another key factor to control particle size is interfacial energy, which also markedly influences kinetic behaviour of precipitation. As shown in Figure $4 a, b$, in the KWN modelling, both interfacial energy and supersaturation driving force can bring significant impact and cause the overlap of nucleation and coarsening regime. However, in the design process, supersaturation expressed as the thermodynamic driving force is the most accessible parameter using the CALPHAD genomic databases. Figure $4 \mathrm{c}$ is a kinetic map calculated by Robson ${ }^{42}$ indicating the correlation between supersaturation and interface energy where nucleation and coarsening can be controlled by both parameters. Experiments are from studies carried out on $\mathrm{Fe}-\mathrm{Cu}^{43} \mathrm{Cu}-\mathrm{Co},{ }^{44}$ $\mathrm{Cu}-\mathrm{Ti}^{45,46}$ and $\mathrm{Ni}-\mathrm{Al}^{47}$ alloys.

Although a design model-chain from CALPHAD thermodynamics and kinetics to phase-level microstructural information is developed and can be directly used as a robust tool for Materials by Design, some constraints require further development of the sharp-interface model. For example, the current KWN modelbased simulations assume a spherical geometry for the secondphase particle precipitation, which is an oversimplification for rod or plate shape precipitates, e.g., $\mathrm{Q}$ phase in the $\mathrm{Al}-\mathrm{Cu}-\mathrm{Mg}-\mathrm{Si}$ based alloy systems. A compromising method is to simulate precipitate kinetics by assuming spherical particles of equivalent particle volume. However, such a compromise could deviate significantly from experimental observation, and should be applied with caution for design purposes.

A less efficient but sometimes useful method which may circumvent the above difficulties by considering geometrical/ crystal anisotropy is the so-called phase-field model (PFM) or diffuse interface model. For the sake of the process-structure modelling, the governing functionals of PFM are equivalent to the time-dependent Ginzburg-Landau equation ${ }^{48}$ and Cahn-Hilliard equation. ${ }^{49}$ Similar to the case of sharp-interface KWN model, both approaches take fundamental thermodynamic and kinetic parameters as the input, which can be read from the CALPHAD databases. In addition, PFM also experiences the difficulties of determining several key input parameters, such as, interfacial energy, gradient energy term and interfacial mobility, which are generally hard to measure, without even further considering their time and temperature dependence. It is noteworthy, even though PFM of anisotropic structure is feasible, the anisotropic input parameters, e.g., interfacial energy, often require a good quantitative estimation, which is still a daunting task for both atomistic modelling and experiments. Therefore, more often, these input parameters are still considered as the fitting parameter to perform the simulation to reach a good agreement with experimental microstructural evolution.

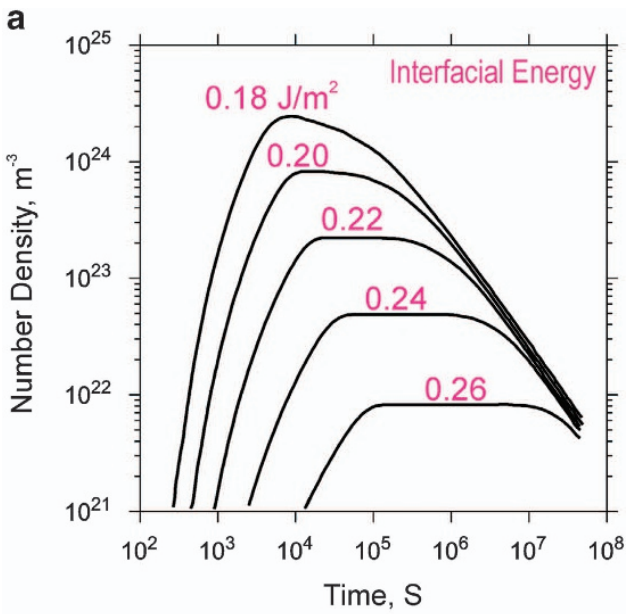

b
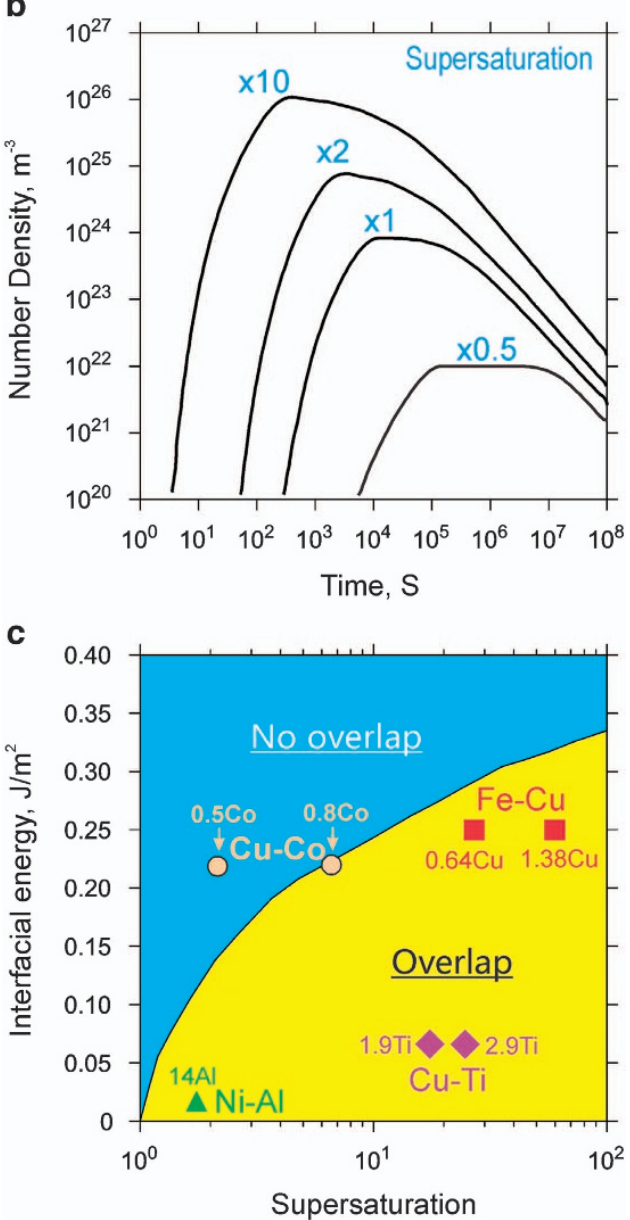

Figure 4. Predicted evolution of number density with time for a selected range of (a) interfacial energies and (b) supersaturation. (c) Kinetic map showing the overlap region of nucleation and coarsening influenced by supersaturation and interfacial energy. Simulations are all based on the work performed by Robson. ${ }^{42}$ Alloy compositions are given in atomic percentage. Figure is reprinted with permission from Elsevier.

Figure 5 shows the relation among CALPHAD, experiments, sharp-interface (KWN) and diffuse interface models (PFM) for a typical process-structure simulation of solid-state precipitation phenomena. Although PFM can also be performed based on the CALPHAD method, nowadays it is still a significant challenge for effective coupling with CALPHAD database for multicomponent 


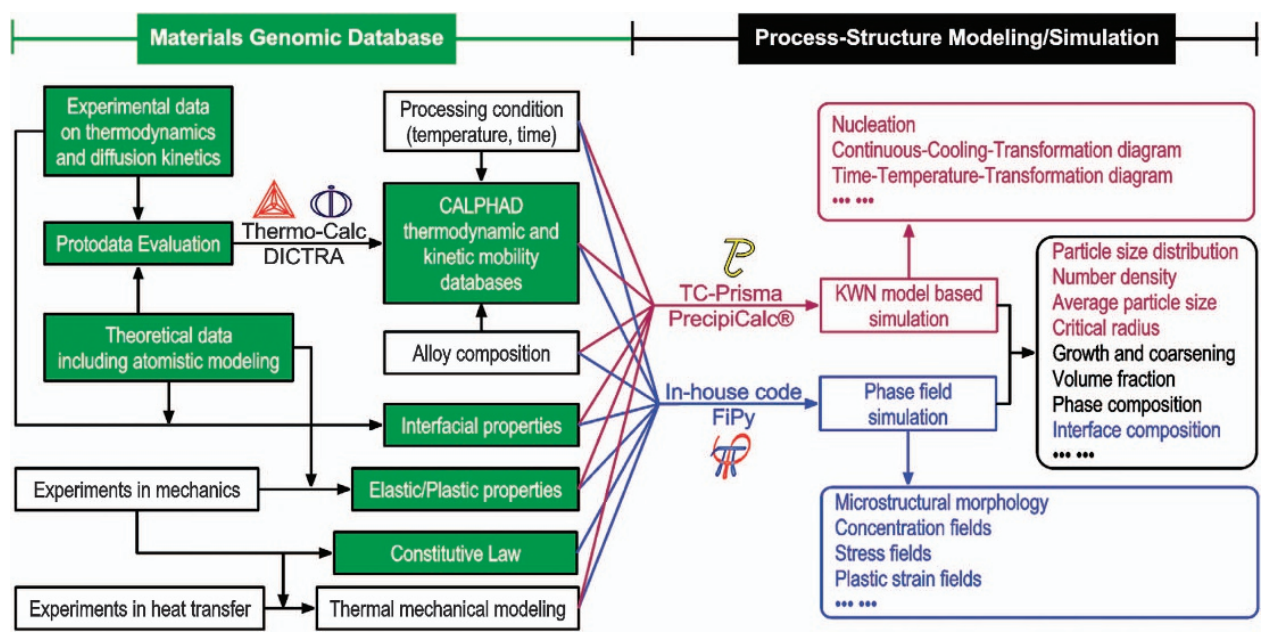

Figure 5. Flow chart of process-structure modelling of solid-state transformation for second-particle growth. Both KWN model-based simulation and phase-field simulation take materials genomic database for the model input. The unique outputs of these two different simulation techniques are highlighted in purple (KWN) and blue (phase-field).

and multiphase simulations ${ }^{50,51}$ owing to the multiplicity of both bulk and interfacial properties. Another distinctive disadvantage of PFM is its limitation on simulating nucleation stage by generating nucleation sites using some ad hoc methods. Overall, in a practical simulation, comparing with KWN methods, PFM usually contains more adjustable parameters, which are not easy to determine, despite its capability of handling more complex phenomena. Nevertheless, PFM is often a useful science tool to enhance understanding of mechanism, it is generally less useful as an engineering tool than KWN-based methods that also provide better-defined statistical quantities.

A parametric design often relies on efficient computational design toolkits. Because the KWN model-based simulations can be implemented in an intuitive way by coupling with fundamental CALPHAD thermodynamic and kinetic parameters, they are widely adopted in the process-structure design. The PrecipCalc software developed by the QuesTek Innovations (Evanston, IL, USA) is a good example utilising the sharp-interface precipitation model for alloy design and process optimisation, which led the commercialising of several Ferrium high-performance alloys, e.g., S53, M54, C61 and C64. ${ }^{52}$

\section{Structure-property relation and design models}

As shown in Figure 3, strength, toughness, creep and fatigue are four elementary mechanical properties of importance in structural materials design. Although corrosion resistance is also important, it is commonly treated as a composition constraint while improving these four elementary properties. It is a formidable task to cover all of the structure-property linkage models in this review. For elucidating the application of structure-property models to linkage design, in this section, we selectively discuss some well-developed mechanical models, which are available for application, by citing some practical structural alloy designs. As indicated in Figure 2, whereas analytical models are available for improving strength and creep, toughness and fatigue are optimised by performing micromechanical finite element analysis (FEA).

Structure-strength. One of the most well-developed structureproperty analytical models is probably the one for predicting mechanical strength based on alloy hardening mechanism. Table 1 shows a summary of elementary hardening mechanism of materials strength by Hornbogen. ${ }^{53}$ Therefore, the microstructure from zero- to three-dimensional (3D) discontinuities are defined as the source of elementary hardening mechanism.
Table 1. Summary of elementary hardening mechanism of crystalline phases $^{53}$

\begin{tabular}{lll}
\hline Symbol & Obstacles & Hardening mechanisms \\
\hline$\sigma_{0}$ & Lattice friction, order & Order hardening \\
$\Delta \sigma_{\mathrm{s}}$ & Solute atoms, vacancies & Solid solution hardening \\
$\Delta \sigma_{\mathrm{d}}$ & Dislocations & Work hardening \\
$\Delta \sigma_{\mathrm{b}}$ & Grain- or phase- & Grain boundary hardening \\
& boundaries & \\
$\Delta \sigma_{\mathrm{p}}$ & Particles & Precipitation hardening \\
$\Delta \sigma_{\mathrm{ac}}$ & Crystal anisotropy & Texture hardening \\
$\Delta \sigma_{\mathrm{am}}$ & Microstructure & Fibre hardening \\
& anisotropy & \\
$\Delta \sigma_{\mathrm{m}}$ & Crystal metastability & Pre-martensitic softening, \\
& & transformation hardening \\
\hline
\end{tabular}

Excellent examples of applying such rules for materials strengthening can be found in the hardening enhancement design for high strength steels. ${ }^{54,55}$ Typically, overall yield strength is described using the superposition law:

$$
\sigma_{Y}=M\left[\tau_{0}+\sum_{i} \tau_{i}\right]+\sigma_{\mathrm{HP}}
$$

where $M$ represents the Taylor factor, $\tau_{0}$ is the Peierles-Nabarro stress contribution, ${ }^{56-58}$ which often adopts the intrinsic value of the pure base alloy. $\tau_{i}$ takes into account contributions from work hardening $\tau_{\mathrm{W}}$, solid solution strengthening $\tau_{\mathrm{SS}}$ and precipitation strengthening $\tau_{\mathrm{p}}$. The Hall-Petch effect $\sigma_{\mathrm{HP}}$ is the strengthening caused by grain refinement. Different contributions to the yield strength model is listed in Table 2. On the basis of the alloy composition and processing time, $\sigma_{\mathrm{P}}$ in Table 2 representing the dispersed particle strengthening contribution can be modelled based on the size of obstacle precipitates. As illustrated in Figure $6 a$, as a start, the small shearable particles follow the Friedel stress; with particle growth, the Orowan bypass stress becomes dominant, decreasing with the incremental particle size. However, in the case of ordered precipitate strengthening for superalloys, due to the antiphase boundary behaviour with paired dislocations, the peak hardening usually arrives earlier than the case with single-dislocation interaction with particle obstacles as shown in Figure $6 a{ }^{59-61}$ In this case, the peak-aged state corresponds to the intensity of pair dislocation interaction with obstacle particles.

A recent study performed by Wang et al. ${ }^{54}$ demonstrated the application of the above superposition law on predicting the yield 
Table 2. Contributions to yield strength by considering effects of solution strengthening, precipitation strengthening, work hardening, Hall-Petch effects based on intrinsic strength due to Peierles-Nabarro stress ${ }^{54}$

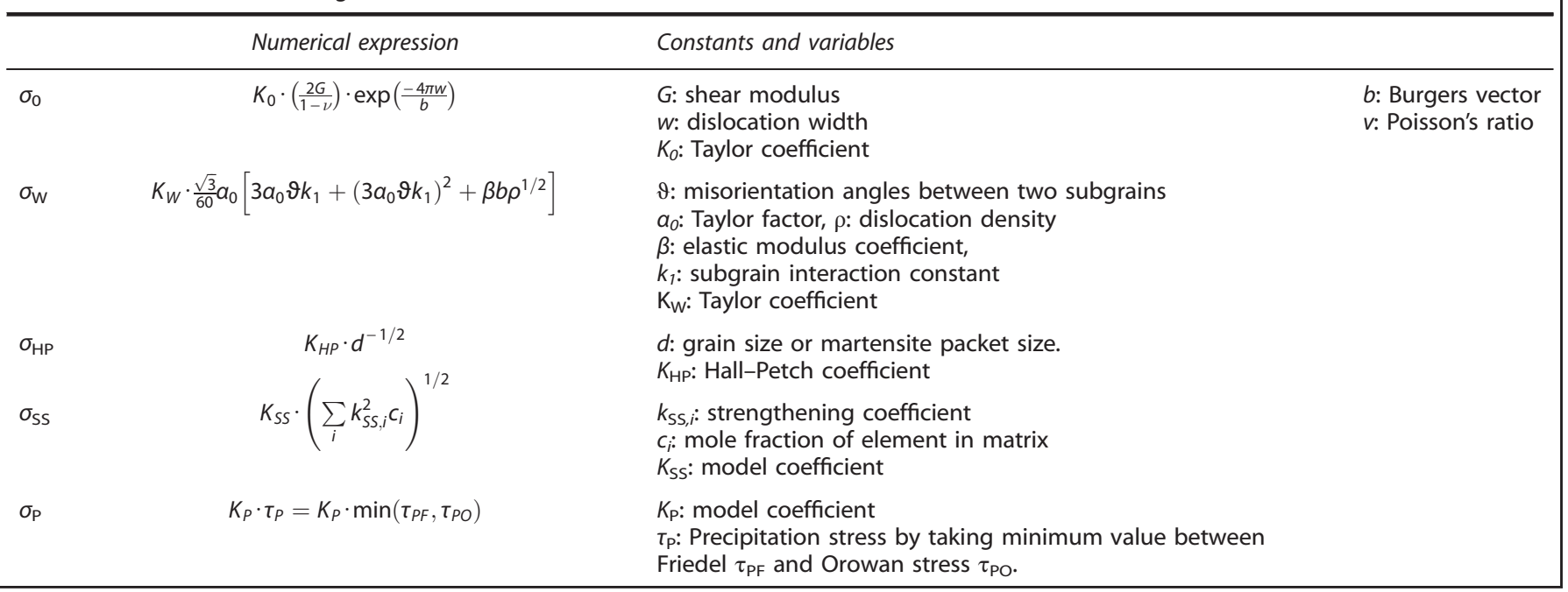

strength of a secondary-hardening steel Blastalloy 160. A new transformation strengthening model accounting for $\mathrm{Cu}$ particle phase transformation was developed by associating with dislocation interaction with $\mathrm{Cu}$ of different crystal structure (bcc, 9R martensite and $\mathrm{fcc}$ ). In addition, a modified predictive yield strength model was developed based on 3D APT of $\mathrm{M}_{2} \mathrm{C}$ and bcc $\mathrm{Cu}$-hardening precipitates. Especially, to directly link quantitative grain structure characterisation and yield strength, 3D precipitate size distribution and characterisation parameters (e.g., phase composition, phase fraction) measured by 3D APT were adopted in the strengthening model for predicting yield strength within $10 \%$ uncertainty. Such a method can directly bridge the aforementioned process-structure and structure-property models for improving yield strength as long as all input physical parameters can be well-determined with high accuracy. Therefore, a comprehensive scenario for modelling dispersed particlehardening uses the process-structure model to obtain desired kinetic behaviour of the particle dispersion (see Figures $6 c-e)$. The structure-strength model can determine the optimal particle radius to reach the maximum strengthening as shown in Figures $6 a, b$ providing a clear microstructural objective for design.

Structure-toughness. Materials design is clearly a delicate compromise of a number of controlling parameters, which may be beneficial to one type of mechanical properties, but detrimental to the other. A classic example is the intrinsic inverse proportionality of toughness to materials strength. A specific example of designing Co-Ni ultra-high strength (UHS) steels is illustrated in Figures 7 and 8, which summarize a systems design effort on improving both strength and toughness synchronously. Refining grain size can be beneficial to both strength and toughness, but it is not always achievable. Therefore, understanding multiple ways to maximise both strength and toughness using structure-toughness models is crucial to a successful design.

Much research on toughness mechanism of high strength steels is devoted to avoidance of brittle fracture failure modes such as intergranular fracture. In a systems design for Co-Ni UHS steel, several methods were applied for improving both toughness and strength synergistically in the steel research group (SRG) consortium centred at Northwestern University. ${ }^{15,62-68}$ The related design efforts for enhancing both strength and toughness are summarised in Figure 8, which focuses on (i) ductile-brittle transition temperature (DBTT), ${ }^{69,70}$ (ii) enhancement of interphase chemical bonding to delay microvoid softening and (iii) transformation toughening. Further, as hydrogen embrittlement can promote brittle intergranular fracture, grain boundary (GB) chemistry optimisation is also a primary requirement as indicated in Figures 7 and 8.

On the heuristic level, DBTT is often a primary design parameter to avoid brittle fracture at desired service temperature. An analytical 'master curve' model based on the shift of DBTT was constructed for designing the SRG UHS steels ${ }^{69}$ by considering the influence of weight per cent of key components, hardness and grain size as primary model variables. Such a model directly correlating with alloy composition made it possible to create a criteria for optimising $\mathrm{Ni}$ and Co content in the Co-Ni UHS steel design by making trade-off among toughness, strength and Martensite start temperature.

In the course of the UHS SRG steel designs, the submicron microstructure design for improving ductile toughness and retain high strength is based on suppressing microvoid softening and introducing dispersed-austenite transformation toughening. It is well-established that microvoid nucleation during plastic deformation accelerates ductile fracture via a process of shear localisation, whereby sudden microvoid nucleation destabilises plastic flow by strain location into shear bands. ${ }^{64,71}$ However, the quantitative role of fine $\sim 0.1-\mu \mathrm{m}$ scale secondary particle dispersion which nucleate the microvoids is less well-understood. In an optimised microstructure, these small particles correspond to the Zener-pinning particles ${ }^{72-74}$ acting as the necessary grain refiners. Considerable efforts have been made by the SRG consortium developing several generations of multiscale ductile fracture simulators ${ }^{75-79}$ to quantify the role of this level of microstructure. Extensive efforts were made on micromechanical FEA combined with the DFT calculation of interfacial strength, ${ }^{75,76,80-83}$ which can evaluate ideal work of adhesion. For example, in the work by Hao et al. ${ }^{75,76}$ a hierarchical constitutive model was derived with the plastic potential by considering DFT-calculated interfacial debonding and microvoid softening effects. Such an effort directly bridges atomistic modelling and continuum finite element simulation, which offers deeper insights into correlation between strength and fracture toughness. Furthermore, the interfacial adhesion energy can be enhanced by controlling dispersed phase compositions and geometric features in the design process using process-structure models.

On the basis of these simulations, a phenomenological model of toughness related to microvoid nucleation ${ }^{84-86}$ was developed to 

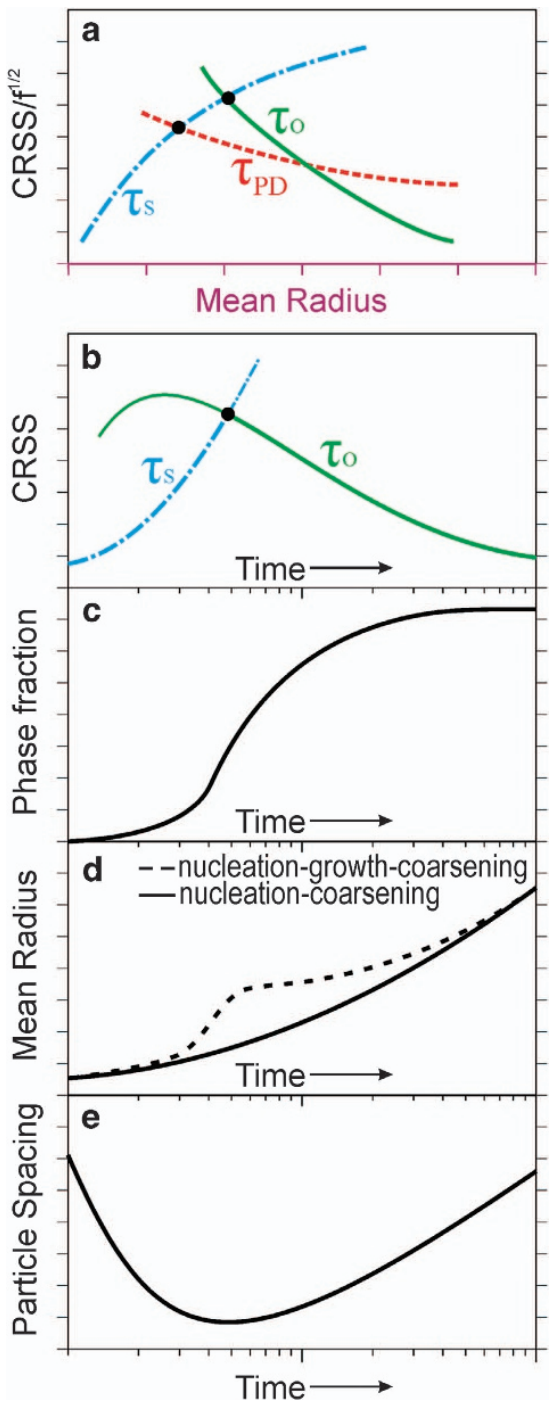

Figure 6. Schematic representation of dispersed particle strengthening mechanism governed by process-structure-property-performance paradigm. (a) relation between normalised critical resolved shear stress (CRSS) using square root of the volume fraction for the second-phase strengthening particle $\mathrm{f}^{1 / 2}$ and mean particle radius. Blue chain line denotes shear stress, red-dashed curve corresponding to the interaction between paired dislocation and obstacle, and the green curve is for Orowan looping effects. (b-e) show kinetic evolution of CRSS, particle phase fraction, mean radius and particle spacing.

aid parametric design of ductile toughness. According to the model developed by Wang and Olson, ${ }^{84}$ the limit of ductile fracture toughness can be quantitatively related to the critical strain for shear localisation governing primary void coalescence.

As illustrated in Figure 8, another interface level design concept for avoiding environmental GB embrittlement is the GB cohesion enhancement, which is mainly applied to minimise hydrogeninduced intergranular embrittlement. ${ }^{68,87,88}$ As a basis for establishing an understanding on the electronic level, the full-potential augmented planewave (FLAPW) method was applied in a series studies on UHS stee ${ }^{68,87-91}$ based on a thermodynamic theory developed by Rice and Wang. ${ }^{92}$ Their theory describes the mechanism of impurity-induced intergranular embrittlement via the competition between plastic crack blunting and brittle boundary separation. The derived 'embrittlement potency' is defined as the segregation energy difference between segregant species along the $\mathrm{GB}$ and free surface (FS), $\Delta E_{\mathrm{GB}}-\Delta E_{\mathrm{FS}}{ }^{80,82,92}$ which indicates a species as a cohesion enhancer when this quantity is negative. Rice and Wang ${ }^{92}$ directly correlated this quantity with measured embrittlement sensitivity quantities, relating intergranular DBTT and interfacial segregant atomic fraction. Accurate prediction of this quantity based on FLAPW were then performed by the SRG at the Northwestern University. ${ }^{89,91}$ Combining initial FLAPW calculations and handbook quantities, such as elemental cohesive energies, a simplified model was developed to predict potencies represented in Figure $9 .{ }^{89}$ To quantify the accuracy of this simplified model, several rigorous validation FLAPW calculations were performed (solid points in the inset of Figure 9), and confirmed that W and Re exhibit the highest cohesion enhancement. Eventually, a genomic surface thermodynamic database was constructed to enable design of the $\mathrm{GB}$ composition to entirely eliminate the intergranular mode of hydrogen embrittlement. ${ }^{55,87,88}$

In addition to these methods of increasing GB cohesion and interfacial bonding between matrix and particles, transformation plasticity was further introduced to improve toughness during plastic deformation in the mechanical Co-Ni UHS steels as shown in Figure 8. A key design parameter is the transition temperature called $M_{S}^{\sigma}$, below which stress-assisted martensitic transformation controls materials yielding. As quantified by the Olson-Cohen theory, ${ }^{93,94}$ below $M_{S}{ }^{\sigma}$, the transformation controlled yield stress rises due to the stability of the parent austenite increasing with temperature. Above $M_{S}^{\sigma}$, the slip-controlled yield stress decreases with temperature through thermal activation of dislocation motion. Controlling the stability of the austenite phase qualified by $M_{S}{ }^{\sigma}$ is the key to optimising transformation toughening. In the studies by Leal ${ }^{95}$ and Stavehaug, ${ }^{96}$ the $M_{S}^{\sigma}$ temperature was further characterised by distinguishing between that defined by uniaxial tension $M_{S}{ }^{\sigma}(u t)$ and by the crack tip stress state denoted as $M_{S}{ }^{\sigma}(c t)$. As shown in Figure 10, the uniform ductility reaches a maximum between these two temperatures, and maximum fracture toughness occurs at $M_{S}^{\sigma}(c t)$. To quantitatively design transformation toughness in UHS steel, a model linked with thermodynamic database is proposed by Olson and his colleagues ${ }^{67,97-101}$ in a series of works. The underlining approach is based on an austenite stability parameter (ASP), ${ }^{97,98}$ which can be expressed as:

$$
\Delta G_{c h}\left(x_{i}, T\right)+W_{f}\left(x_{i}, T\right)=-G_{n}-\Delta G_{\sigma}(\sigma, \Delta V / V)
$$

where the first term on the left side of equation is chemical contribution of the total energy, the second term is the interfacial friction energy, where both are functions of temperature $T$ and composition $x_{i}$. The right side of the above equation is composed of defect potency, $G_{n}$, which can be approximated as a constant value for a certain material, ${ }^{97,98}$ and mechanical driving force, $\Delta G_{\sigma}$ which is a function of stress state and strength goal of the material. According to the Olson-Cohen model, ${ }^{93}$ given the stress state of the material and desired $M_{S}^{\sigma}$ temperature, it is possible to provide a critical value for the austenite stability parameter, and thus allow dispersed-austenite composition to be designed through the CALPHAD genomic databases.

Structure-creep/fatigue. Unlike strength and toughness, creep and fatigue are dynamically structure-sensitive properties, where predictive models are more complex. For creep modelling, many available phenomenological models require numerous empirical parameters, and thus generate a heavy load for experiments. However, there is a promising method for parametric design purposes when dynamic creep models are correlated to diffusion kinetic modelling. For example, in single-crystal Ni superalloys, under a high-temperature, low-stress condition, where dislocation climb at the matrix $\gamma$-precipitate $\gamma^{\prime}$ interface becomes the dominant rate-controlling step in the kinetic creep process, modelling vacancy flux can be directly employed for creep 


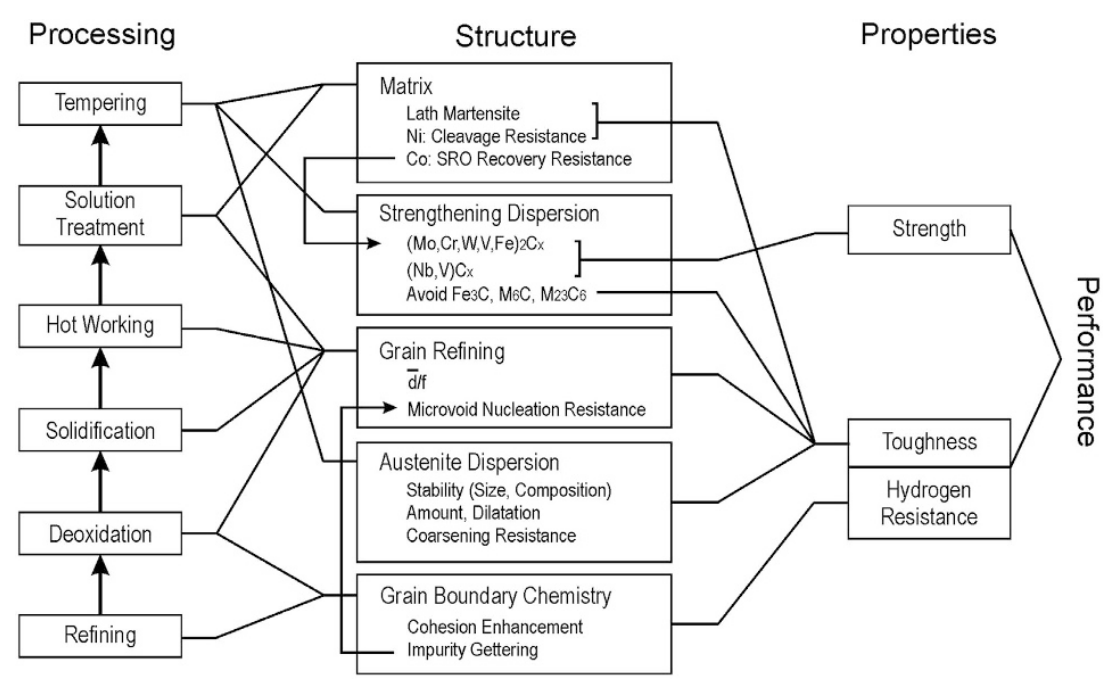

Figure 7. Systems design chart of the Co-Ni UHS steel.

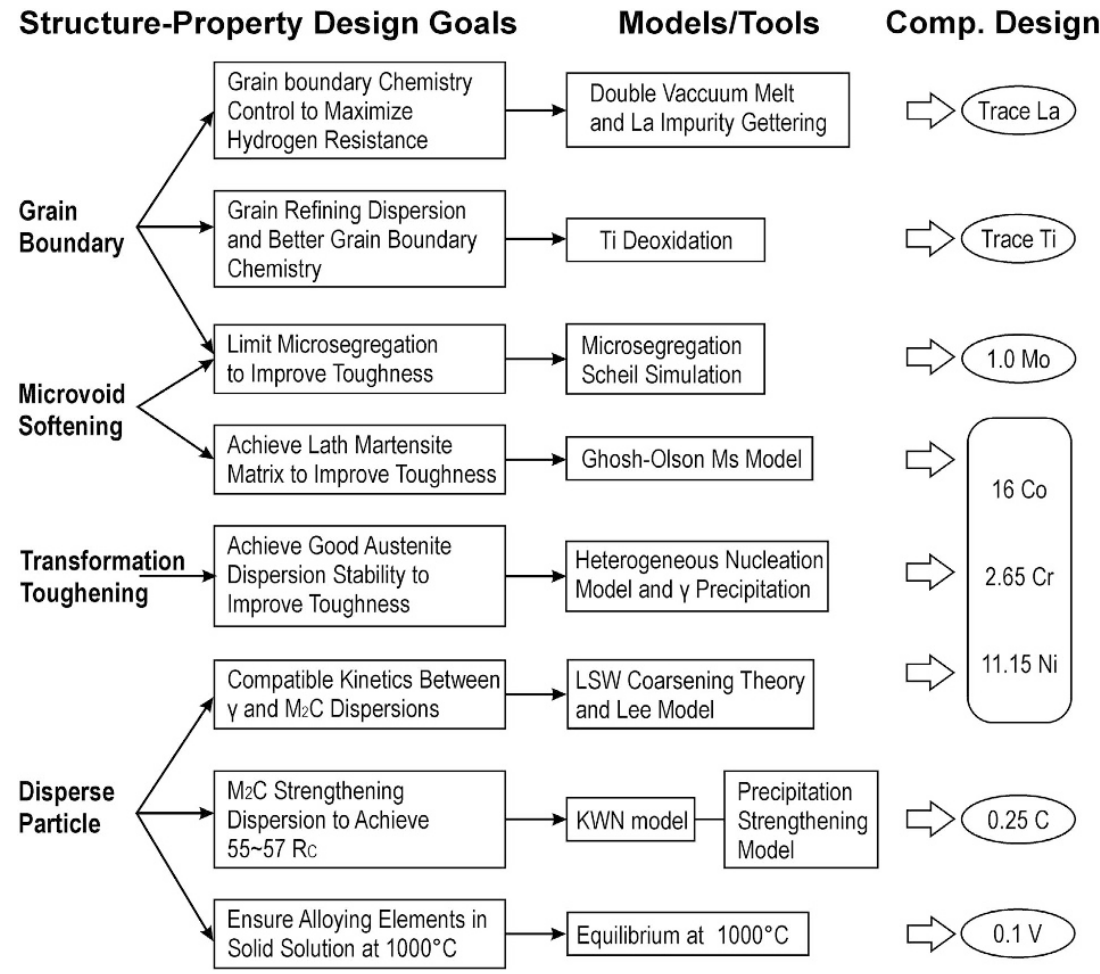

Figure 8. Summary of design goals and models for the Co-Ni UHS steel based on an inversely inductive design approach.

resistance design. Recent studies published by Dyson ${ }^{102}$ and Zhu et al. ${ }^{103}$ provide such promising models with vacancy diffusivity as a key design parameter, which can be calculated using the CALPHAD diffusion database for multicomponent alloy design. Further at very high temperatures, where rafting affects creep, structure-property models can also be related to the CALPHAD genomic database. In the viscoplastic regime described by the Socrate-Parks model, ${ }^{104}$ the thermodynamic driving force for rafting is primaryily controlled by the lattice mismatch of the matrix $y$ and the precipitate $\gamma^{\prime}$, which can be predicted through models ${ }^{105}$ linking to the CALPHAD molar volume databases. ${ }^{106,107}$

With regard to structure-property models for fatigue, as indicated in Figure 2, besides conventional statistical analysisbased phenomenological models, more attention is now paid to micromechanical FEA as a foundation for a predictive probabilistic approach. The state-of-the-art micromechanical FEA on fatigue is comprehensively reviewed by Pineau et al. ${ }^{108}$ highlighting the seminal contributions of McDowell ${ }^{108}$ and his former students. Fatigue is an intrinsically multiscale and multistage phenomenon, and thus highly sensitive to microstructure level design. Conventional fatigue modelling separates the total life into two stages: initiation life $N_{i}$ and crack propagation life defined by number of cycles $N_{\mathrm{p}}$. For low cycle fatigue, $N_{\mathrm{p}}$ dominates, and thus can be modelled by statistical methods via some parametric scaling law (e.g., the Coffin-Manson law $^{109}$ ). In contrast, fatigue crack initiation dominates the total life of (ultra) high cycle fatigue. Therefore, it should be predictable by the micromechanical model with process-microstructure sensitivity. A recent thesis work by Moore ${ }^{110}$ further developed the micromechanics-based method for multiscale fatigue nucleation prediction, which successfully 


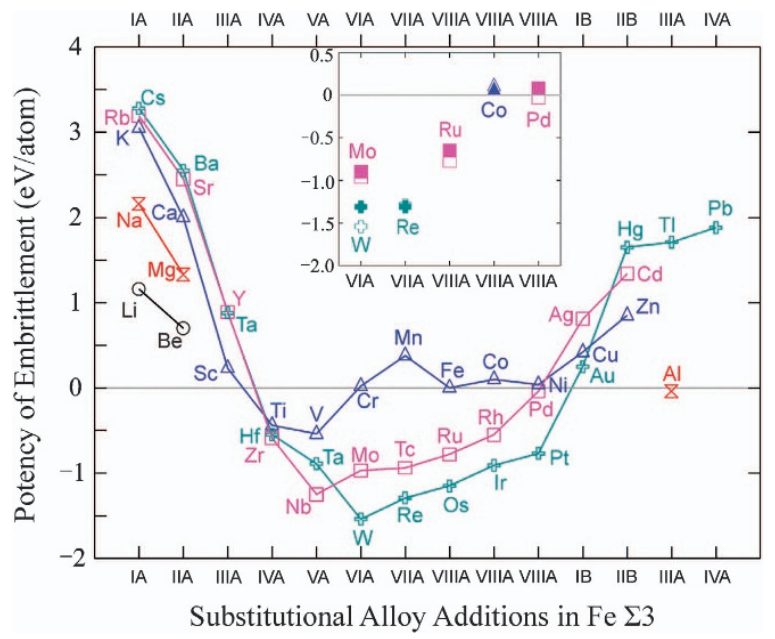

Figure 9. Embrittlement potency prediction made for substitutional elements in Fe grain boundaries. ${ }^{89}$ Solid points in inset represent FLAPW calibration/validation results. ${ }^{55}$

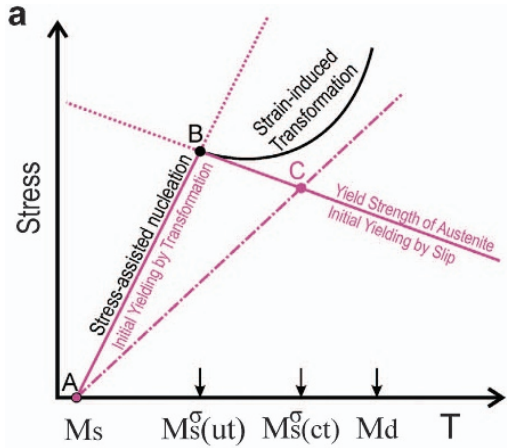

b

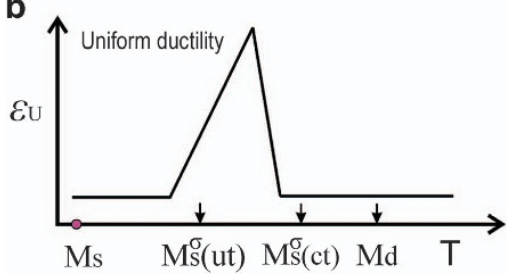

c

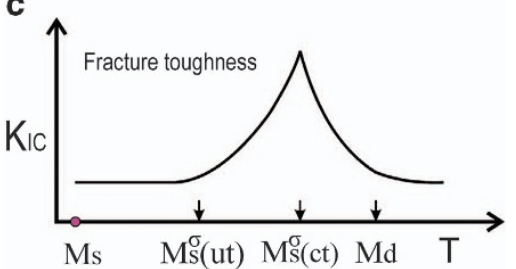

Figure 10. (a) Schematic representation of interrelationships between stress-assisted and strain-induced martensitic transformation. (b) Uniform ductility $\varepsilon_{U}$ as a function of temperature. (c) Fracture toughness $\mathrm{K}_{\mathrm{IC}}$ as a function of temperature.

predicted the fatigue behaviour of the $\mathrm{Ni}-\mathrm{Ti}$ shape memory alloy. The 3D image-based micromechanical FEA demonstrates that an alloy design with enhanced yield strength can significantly increase fatigue strength in addition to the effects of minimising inclusion size. It should be emphasised that such micromechanical FEA for ultra-high cycle fatigue simulation directly drove a shape memory biomedical alloy design ${ }^{111,112}$ performed synchronously. It was determined that a $50 \%$ increase in $\mathrm{Ni}-\mathrm{Ti}$ yield strength resulted in a $44 \%$ increase in ultra-high cycle fatigue limit at $10^{9}$ cycles.
We note that, in a practical design, although a completely deductive process-structure-property model focusing on sequential cause and effects is difficult to obtain, an inversely inductive design approach directed by moving fundamental design parameters in the right direction is usually sufficient to implement a hierarchical design using specific means based on the available mechanistic models of Materials by Design.

\section{AIM: ACCELERATING TECHNOLOGY TRANSITION}

As indicated in the ICMD hierarchical architecture (see Figure 1), the AIM method completes the process of component-level materials development. Here, final design allowables bounded by the process-structure-property models are evaluated deliberately. To fully implement AIM, an integrated product team consisting of original equipment manufacturer, small company, university and government laboratory are often assembled determining design goals, sharing information and integrating available design models/tools within the framework now known as ICME.

Although the above described process-structure-property models in Materials by Design is utilised extensively in AIM as a basis, there are three additional unique thrusts in the AIM method, which includes (i) multidisciplinary engineering model integration, (ii) location-specific modelling throughout a component and (iii) uncertainty quantification and management.

Standard statistical methods are naturally vital for uncertainty quantification, which guides design tolerances. Such techniques were applied in the aforementioned design of the UHS steel, Ferrium S53 by the SRG consortium, run concurrently with the DARPA-AIM project. Design sensitivity analysis was performed using a combined method of Monte Carlo simulation and iCMD (an integrated computational materials design software package created by QuesTek Innovations LLC, Evanston, IL, USA), implemented through the commercial iSIGHT design optimization platform. For example, within 12 min on a Pentium IV 2.2 GHZ CPU (QuesTek Innovations LLC), a thousand parametric of structureproperty $\mathrm{iCMD}$ calculations using the three- $\sigma$ limits of the composition and process temperature tolerances generated the probability distribution of Charpy V-Notch toughness, hardness, Martensite start temperature and DBTT.

Under the DARPA-AIM 3-year project starting from 2000 using the example of IN100 superalloy turbine disks, the iSIGHT design integration system was adopted as the cross-disciplinary platform to link distributed software capabilities in Utah and Illinois as shown in Figure 11a. The turbine disk heat treatment process modelling performed using a FEA-based DEFORM Heat Treatment module (Scientific Forming Technologies Corporation, Columbus, $\mathrm{OH}, \mathrm{USA}$ ) determined the history of temperature profile at every location in a part, which were taken as the input of the precipitation simulator, PrecipiCalc (QuesTek Innovations LLC), for the process-structure modelling. In the final step, a yield strength structure-property model was applied to predict the strength at both room temperature and elevated temperatures by taking results of PrecipiCalc and a CALPHAD-prediction of antiphase boundary energies as the input. The efficiency and high fidelity inherited from the Materials by Design models for the AIM methodology can be reflected by the quantitative simulation of structure and yield strength for the disk centre location. By tuning parameters of interfacial property and diffusivity through model-calibration performed at the University of Connecticut, the dynamic behaviour of the strengthening particle can be quantitatively captured using PrecipiCalc simulation with a high accuracy. ${ }^{13}$ Figures $11 \mathrm{~b}, \mathrm{c}$ shows the time evolution of mean sizes and fractions of three $\gamma^{\prime}$ populations under a three-step heat treatment cycle. To further perform a location-specific design, process-structure-property models were applied to an entire minidisk as shown in Figures $11 \mathrm{~d}$,e. The calculated spatial contours of secondary $\gamma^{\prime}$ size show high consistency with 


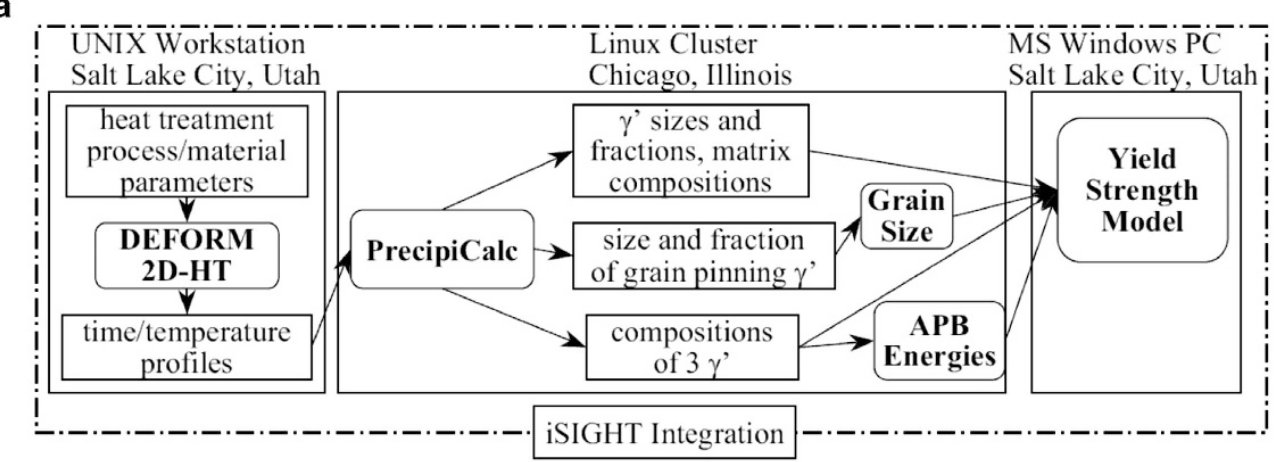

b

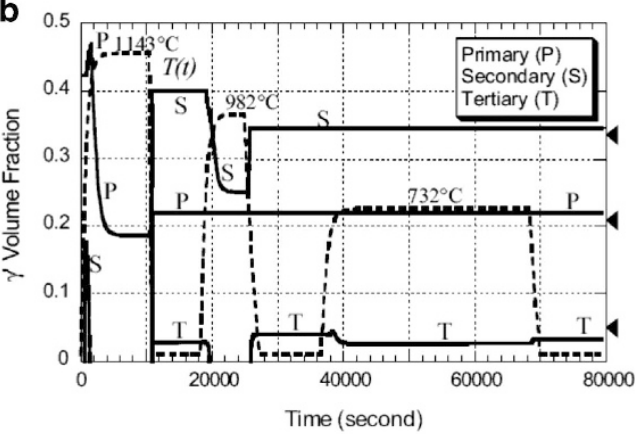

d

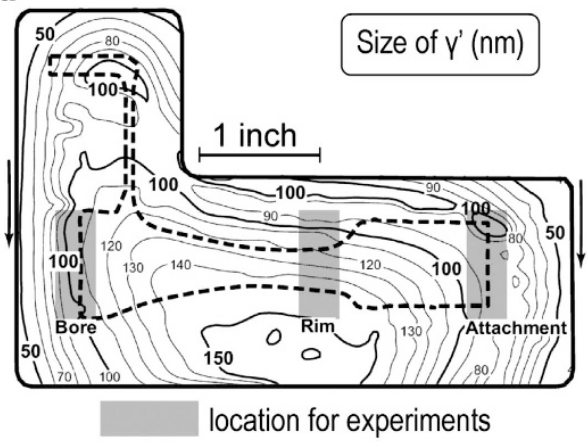

C

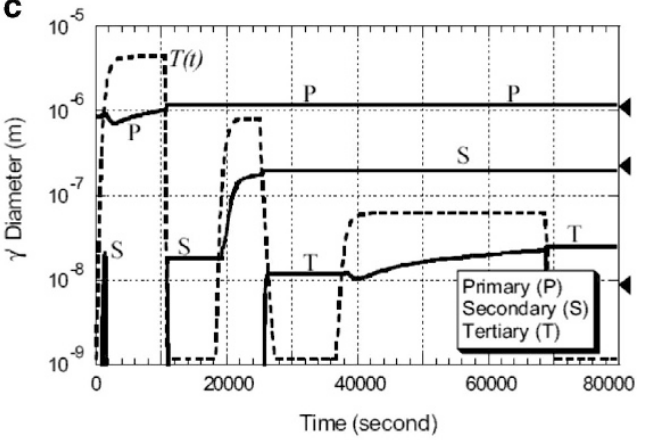

e

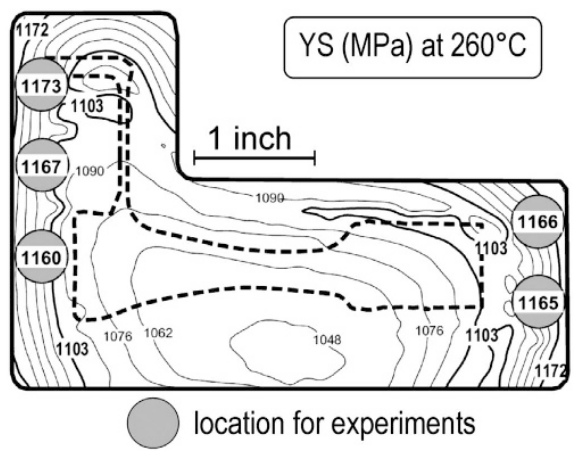

Figure 11. (a) Distribution iSIGHT integration for mechanistic process-structure-property simulations in the DARPA-AIM project, performed on different computer hardware and operating systems across network. (b,c): Kinetic simulation performed using PrecipiCalc for a centre location of an aero-turbine disk under the three-step heat treatment cycle. Time evolutions of mean sizes and fractions of three $\gamma^{\prime}$ distributions are shown in solid curves overlapping with temperature profile as dashed curve. Experimental $\gamma^{\prime}$ microstructural results are indicated by solid triangles on the right. (d) Calculated spatial contours of secondary $\gamma^{\prime}$ size $(\mathrm{nm})$ for a radially symmetric cross-section of the minidisk. The disk is immersed into quenching media from bottom to top denoted by side-arrows. (e) Calculated spatial contour of yield strength ( $\mathrm{MPa}$ ) at $260{ }^{\circ} \mathrm{C}$ for minidisk. Figure is reproduced based on the work performed by Jou et al. ${ }^{113}$ Figure is reprinted with permission. Copyright 2004 by The Minerals, Metals \& Materials Society.

experimental observation on bore, rim and attachment parts indicated with shaded rectangles in Figure $11 \mathrm{~d}$. Using the structure-strength model, the tensile yield strength at five different locations was predicted within quantified uncertainty ranges by comparing with experimental results on specific locations (see circles highlighted in Figure 11d.

As a follow-on to the DARPA-AIM programme, a National Aeronautics and Space Administration-funded project at QuesTek Innovations in 2005-2008 further extended the above AIM techniques for a hierarchical calibration/validation uncertainty management approach for all available process-structure models $^{31}$ for a Dual Microstructure Heat Treatment (DMHT) process design indicated in Figure 12. As different locationspecific properties require different microstructures, the design sensitivity of the process-structure model is crucial to meet property requirements. Table 3 summarises the sequential characterisation protocol performed for standard uncertainty quantification of individual inputs in the process-structure models. Subsequently, a hierarchical uncertainty management strategy was adopted by balancing model sensitivity against database intrinsic accuracy. Rigid shifts to second-phase free-energy functions according to Gibbs-Thompson effects were applied for a precise description of the secondary strengthening particles. Meanwhile, DICTRA atomic mobility databases were recalibrated by diffusion couple experiments, which achieved an improved accuracy of diffusivity prediction. Regarding the high sensitivity of interfacial energy in precipitation simulation, PrecipiCalc simulations were carried out by adjusting interfacial energy to match the critical nucleation undercooling accurately determined by the single sensor differential thermal analysis technique, which measures a precise thermal history of a rapidlyquenched 3-mm diameter pins. ${ }^{31,32}$ Afterwards, the PrecipiCalc simulated microstructural attributes were further compared with the APT characterisation to evaluate uncertainty limits. 


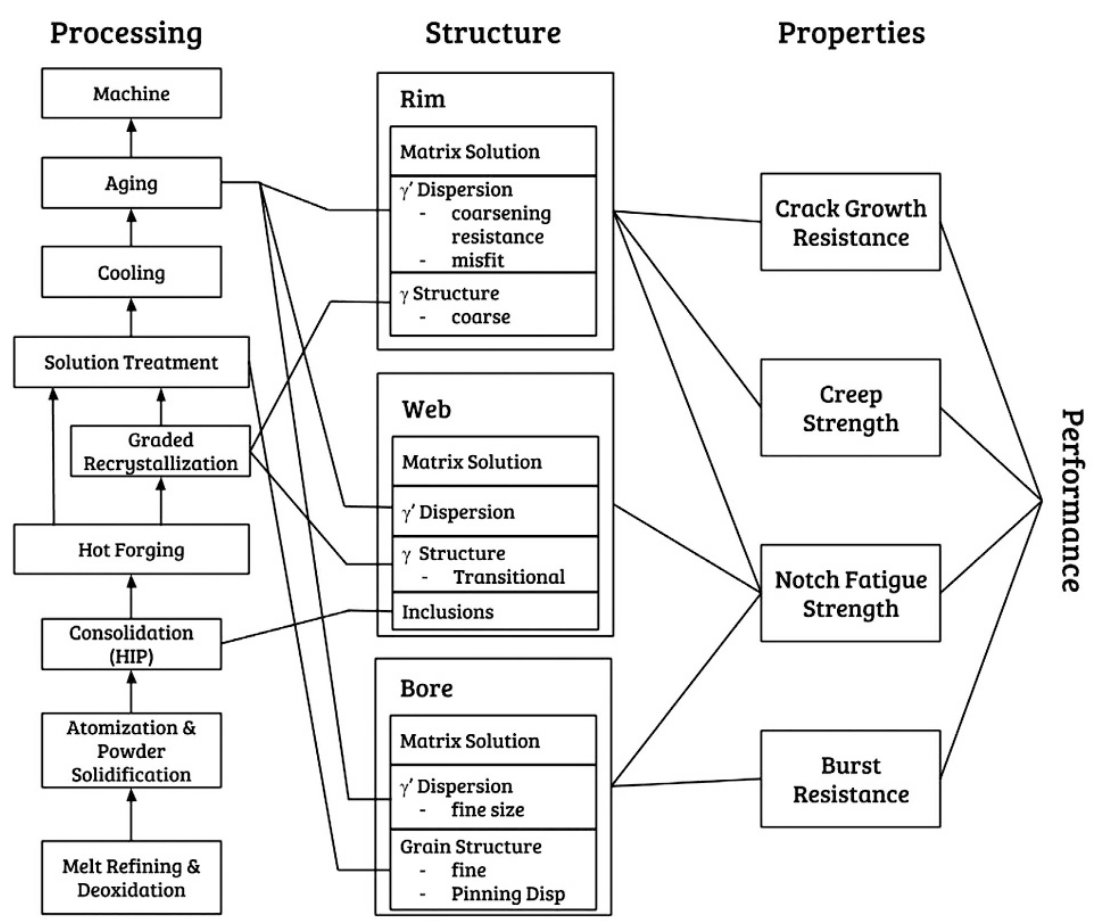

Figure 12. Systems design chart of Ni turbine disk alloy using the AIM method. Hierarchical microstructure are designed for specific locations in the turbine disk.

Table 3. Summary of database, model, calibration and validation protocol for precipitation modelling adopted in the AIM method

\begin{tabular}{lllll}
\hline Database & Quantity & Model & Model parameters & Calibration and validation \\
\hline Thermodynamics & Bulk energy & CALPHAD & Free energy & XRD/EDS/TEM/APT \\
& Interfacial energy & Gibbs-Thompson & $\mathrm{G}_{\mathrm{el}}, \sigma_{\text {coh }}$ & APT/SSDTA \\
Molar volume & Lattice mismatch & CALPHAD & $\mathrm{G}_{\mathrm{el}}, \mathrm{R}$ & XRD/TEM/DFT \\
Kinetics & Atomic mobility & CALPHAD & Mobility & Diffusion couple \\
& $\mathrm{D}_{\text {scale }}$ & & $\mathrm{D}_{\text {scale }}$ & EPMA or WDS \\
\hline
\end{tabular}

Abbreviations: APT, atom probe tomography; DFT, density functional theory; EDS, energy dispersive spectroscopy; $G_{e l}$, estimated elastic coherency energy; $\mathrm{R}$, coherency transition size from coherent to incoherent state; SSDTA: single sensor differential thermal analysis; ${ }^{32}$ TEM, transmission electron microscopy; $\mathrm{XRD}, \mathrm{X}$-ray diffraction.

It should be noted that, having demonstrated the importance of the AIM technique, a suite of advanced 3D tomographic multiscale characterisation tools were further developed under the support of ONR and DARPA. Thus, the AIM technique is now supported by both novel experiments and 3D process-structure-property models reaching a new level of fidelity, which is greatly beneficial to the enterprise of materials cycle compression.

\section{SUMMARY: CYBERMATERIALS INNOVATION BASED ON MATERIALS GENOME}

The continued development of the ICMD techniques, Materials by Design and AIM, is already accelerating materials innovation, thus leveraging the current design techniques in materials science and mechanical engineering, which foster synergistic interactions among disciplines.

Materials by Design and AIM techniques serve as the two major pillars in the ICMD hierarchical architecture. As reviewed in the foregoing sections, sustained efforts have made grand achievements in transferring science-based ideas to industrial production. However, a sustainable development strategy is still needed to fulfil the potential of the ICMD blueprint in Figure 1 for cybermaterials innovations. It is clear that Materials Genome database as the cornerstone has a decisive role.
First, the systems design models of process-structure-propertyperformance paradigm can all benefit from further improvement. For instance, the preceding discussion on Materials by Design has highlighted needs of model development for non-spherical particles in the framework of the KWN model-based simulation. In view of the high sensitivity of nucleation to interfacial energy, more rigorous atomistic modelling of interfacial thermodynamics would enhance predictive capability.

Second, because process-structure linkage design relies heavily on the quality of the fundamental materials genomic databases assembled by computational thermodynamics and kinetics, more dedicated research on constructing high-quality genomic database should be motivated and promoted. Importantly, these research activities also include experiments providing protodata. The so-called high-throughput experiment represented by diffusion multiples ${ }^{114}$ is a good example to make such contributions. Meanwhile, more efforts should be made on bridging the current DFT-based atomistic models and CALPHAD method by extending their temperature scales. ${ }^{115}$ A recent work on the $\mathrm{Fe}-\mathrm{Cr}$ system ${ }^{22}$ demonstrated that the CALPHAD models extended to $0 \mathrm{~K}$ will garner valuable insights into anomalous phenomenon, i.e., negative enthalpy of mixing on Fe-rich side, found in enthalpy of formation generated by DFT calculations. ${ }^{116}$ 
Expending the impact of the structure-property model development, genomic databases of mechanistic constitutive laws for mechanical FEA should be initiated. Such efforts need intimate collaborations between experimentalists and modelling experts in both materials science and mechanical engineering. As mentioned in the above discussion, the state-of-the-art materials design usually considers experimental calibration as an important part in design iterations. Therefore, technical improvement of such experiments for fundamental model-calibration purposes should be a primary effort.

Materials genomic database construction requires corresponding efforts on standardisation and database management as indispensable support. Taking DBTT as an example, although DBTT can be evaluated using Charpy impact energy tests, precise modelling of DBTT is currently data intensive. ${ }^{17,118}$ If a standard of efficient DBTT measurement is available, limitations affecting the accuracy of DBTT will be significantly diminished, and thus improve the DBT model predictability. Further, we note that related topics are often much broader than the research field of materials science, driving the call for collaborative efforts by various scientific and engineering communities.

Last but not least, perhaps the greatest promise of materials development cycle compression is the new opportunity of concurrent design of materials and devices. ${ }^{119}$ Notable achievements have already been demonstrated in the field of consumer electronics which would never have been possible under trial-anderror empirical materials development.

Overall, it is evident that the next generation of cybermaterials innovation applicable across all materials classes will be grounded in ICMD hierarchical architecture powered by an expanded system of materials genomic databases.

\section{ACKNOWLEDGEMENTS}

This work was performed within the CHiMaD Center for Hierarchical Materials Design at the Northwestern Univeristy, funded by the National Institute of Standards and Technology, USA. ICMD and Materials by Design are trademarks of QuesTek Innovations. We are grateful to Professor John Ågren (KTH, Sweden), Dr Qing Chen (Thermo-Calc Software AB, Sweden), Dr Ikumu Watanabe (NIMS, Japan), and Mr Abhinav Saboo (Northwestern University) for stimulating discussions.

\section{COMPETING INTERESTS}

The authors declare no conflict of interest.

\section{REFERENCES}

1. Apelian, D. et al. Accelerating Techology Transition: Bridge the Valley of Death for Materials and Processes in Defense Systems. National Research Council of The National Academies, The National Academes Press, (2004). Available online at: http://www.nap.edu/catalog.php?record_id = 11108 .

2. Holdren, J. P. Materials Genome Initiative for Global Competitiveness. (Executive office of the president national science and technology council, 2011).

3. Pollock, T. M. et al. Integrated Computational Materials Engineering: A Transformational Discipline for Improved Competitiveness and National Security. (National Research Council of the National Academies, The National Academies Press, 2008) Available online at: http://www.nap.edu/catalog/12199.html.

4. Horstemeyer, M. F.. An Introduction to Integrated Computational Materials Engineering (ICME). Integr Comput Mater Eng Met. (John Wiley \& Sons, Inc., 2012).

5. Olson, G. B. Preface to the viewpoint set on: the Materials Genome. Scr. Mater. 70, 1-2 (2014).

6. Kaufman, L. \& Ågren, J. CALPHAD, first and second generation-birth of the materials genome. Scr. Mater. 70, 3-6 (2014).

7. Campbell, C. E., Kattner, U. R. \& Liu, Z. K. File and data repositories for Next Generation CALPHAD. Scr. Mater. 70, 7-11 (2014).

8. Bhadeshia, H. K. D. H. Computational design of advanced steels. Scr. Mater. 70, 12-17 (2014).

9. Christensen, S. \& D'Oyen, R. Computational formulation of a new composite matrix. Scr. Mater. 70, 18-24 (2014).

10. Olson, G. B. \& Kuehmann, C. J. Materials genomics: from CALPHAD to flight. Scr. Mater. 70, 25-30 (2014).
11. Yuan, Y. et al. A new method to strengthen turbine disc superalloys at service temperatures. Scr. Mater. 66, 884-889 (2012).

12. Yuan, Y. et al. Deformation mechanisms in a new disc superalloy at low and intermediate temperatures. Scr. Mater. 67, 137-140 (2012).

13. Reed, R. C., Tao, T. \& Warnken, N. Alloys-By-Design: Application to nickel-based single crystal superalloys. Acta. Mater. 57, 5898-5913 (2009).

14. Olson, G. B. Computational design of hierarchically structured materials. Science 277, 1237-1242 (1997).

15. Olson, G. B. Genomic materials design: the ferrous frontier. Acta. Mater. 61, 771-781 (2013).

16. Martinetti, L. et al. A critical gel fluid with high extensibility: the rheology of chewing gum. J. Rheol. 58, 821-838 (2014).

17. D'Oyen, R. M.. Systems Design of Case Hardened Polymers for Gears, Doctoral thesis Northwestern University, (1997).

18. Saunders, N. \& Miodownik, A. P. CALPHAD (Calculation of Phase Diagrams): A Comprehensive Guide Pergamon Mater Ser. Pergamon, (1998). Available online at: http://dx.doi.org/10.1016/S1470-1804(98)80019-9.

19. Xiong, W., Xie, W., Shen, C. \& Morgan, D. Thermodynamic modelling of the U-Zr system—a revisit. J. Nucl. Mater. 443, 331-341 (2013).

20. Xiong, W., Xie, W. \& Morgan, D. Thermodynamic evaluation of the Np-Zr system using CALPHAD and ab initio methods. J. Nucl. Mater. 452, 569-577 (2014).

21. Xiong, W., Du, Y., Lu, X., Schuster, J. C. \& Chen, H. Reassessment of the Ce-Ni binary system supported by key experiments and ab initio calculations. Intermetallics 15, 1401-1408 (2007).

22. Xiong, W. et al. An improved thermodynamic modelling of the $\mathrm{Fe}-\mathrm{Cr}$ system down to zero kelvin coupled with key experiments. CALPHAD 35, 355-366 (2011).

23. Xiong, W. et al. Construction of the Al-Ni-Si phase diagram over the whole composition and temperature ranges: thermodynamic modelling supported by key experiments and first-principles calculations. Int. J. Mater. Res. 99, 598-612 (2008).

24. Hallstedt, B. \& Liu, Z.-K. Software for thermodynamic and kinetic calculation and modelling. CALPHAD 33, 265 (2009).

25. Lukas, H., Fries, S. G. \& Sundman, B. Computational Thermodynamics: The Calphad Method (Cambridge University Press, 2007).

26. Andersson, J.-O., Höglund, L., Jönsson, B., Ågren, J. in Proc Metall Soc Can Inst Min Metall (ed. Purdy G.) 153-163 (Pergamon, 1990). Available online at: http://dx.doi.org/10.1016/B978-0-08-040412-7.50023-2.

27. Borgenstam, A., Engstrom, A., Hoglund, L. \& Agren, J. DICTRA, a tool for simulation of diffusional transformations in alloys. J. Phase Equilibria. 21, 269-280 (2000).

28. Xiong, W. CALPHAD-based integrated computational materials engineering research for materials genomic design. JOM 67, 1864-1865 (2015).

29. Bender, M. D. \& Olson, G. B. Designing a precipitation-strengthened, superelastic, TiNi-based alloy for endovascular stentsin Int. Conf. Martensitic Transform 159-166 (John Wiley \& Sons, Inc., 2010).

30. Bender, M. D. \& Olson, G. B. Computational thermodynamics-based design of nanodispersion-strengthened shape memory alloys. in SMST-2007-Proc. Int. Conf. Shape Mem. Superelastic Technol. 115-122 (2008).

31. Olson, G. B. et al. Precipitation model validation in 3rd generation aeroturbine disc alloysin 11th Int. Symp. Superalloys 923-932 (Minerals, Metals and Materials Society, 2008).

32. Alexandrov, B. T. \& Lippold, J. C. Single sensor differential thermal analysis of phase transformations and structural changes during welding and postweld heat treatment. Weld World 51, 48-59 (2007).

33. Wusatowska-Sarnek, A. M., Ghosh, G., Olson, G. B., Blackburn, M. J. \& Aindow, M. Characterization of the microstructure and phase equilibria calculations for the powder metallurgy superalloy IN100. J. Mater. Res. 18, 2653-2663 (2003).

34. Lifshitz, I. M. \& Slyozov, V. V. The kinetics of precipitation from supersaturated solid solutions. J. Phys. Chem. Solids 19, 35-50 (1961).

35. Wagner, C. Theorie der Alterung von Niederschlägen durch Umlösen (OstwaldReifung). Zeitschrift für Elektrochemie, Berichte der Bunsengesellschaft für Phys Chemie 65, 581-591 (1961).

36. Morral, J. E. \& Purdy, G. R. Particle coarsening in binary and multicomponent alloys. Scr. Metall. Mater. 30, 905-908 (1994).

37. Morral, J. E. \& Purdy, G. R. Thermodynamics of particle coarsening. J. Alloys Compd. 220, 132-135 (1995).

38. Kuehmann, C. J. \& Voorhees, P. W. Ostwald ripening in ternary alloys. Metall. Mater. Trans. A 27, 937-943 (1996).

39. Lee, H. M., Allen, S., Grujicic, M. Stability and coarsening resistance of $M 2 C$ carbides in secondary hardening steelsin Innov Ultrahigh-Strength Steel Technol Sagamore Army Mater. Res. Conf. (eds Olson G. B., Azrin M. \& Wright E. S.) 127-146 (U.S. Government Printing Office, 1990).

40. Umantsev, A. \& Olson, G. B. Ostwald ripening in multicomponent alloys. Scr. Metall. Mater. 29, 1135-1140 (1993). 
41. Wagner, R., Kampmann, R., Voorhees, P. W. in Phase Transform Mater (ed. Kostorz G.) 309-407 (Wiley-VCH Verlag GmbH and Co. KGaA, 2005).

42. Robson, J. D. Modelling the overlap of nucleation, growth and coarsening during precipitation. Acta. Mater. 52, 4669-4676 (2004).

43. Kampmann, R., Wagner, R. in At Transp Defects Met by Neutron Scatt SE-12 (eds Janot C., Petry W., Richter D. \& Springer T.) 10, $73-77$ (Springer, 1986).

44. Aaronson, H. I. \& LeGoues, F. K. Assessment of studies on homogeneous diffusional nucleation kinetics in binary metallic alloys. Metall. Trans. A, Phys. Metall. Mater. Sci. 23A, 1915-1945 (1992).

45. Alvensleben, L. V., Wagner, R.FIM-atom probe studies of early stage decomposition in Cu-Ti alloysin Proc 2nd Acta-Scripta Metall. Conf. (eds Haasen P., Gerold V., Wagner R. \& Ashby M. F.) 143-148 (Pergamon, 1984) Available online at: http://dx.doi.org/10.1016/B978-0-08-031651-2.50026-4.

46. Eckerlebe, H., Kampmann, R., Wagner, R. in At Transp Defects Met by Neutron Scatt SE-11 (eds Janot C., Petry W., Richter D. \& Springer T.) 10, 66-72 (Springer, 1986).

47. Wendt, H. \& Haasen, P. Nucleation and growth of $\gamma^{\prime}$-Precipitates in Ni-14 at.\% Al. Acta. Metall. 31, 1649-1659 (1983).

48. Allen, S. M. \& Cahn, J. W. A microscopic theory for antiphase boundary motion and its application to antiphase domain coarsening. Acta. Metall. 27, 1085-1095 (1979).

49. Cahn, J. W. \& Hilliard, J. E. Free energy of a nonuniform system. I. interfacial free energy. J. Chem. Phys. 28, 258-267 (1958).

50. Kitashima, T. Coupling of the phase-field and CALPHAD methods for predicting multicomponent, solid-state phase transformations. Philos. Mag. 88 1615-1637 (2008).

51. Larsson, H. \& Höglund, L. A scheme for more efficient usage of CALPHAD data in simulations. CALPHAD 50, 1-5 (2015)

52. Sebastian, J. \& Olson, G. B. Examples of QuesTek Innovations' Application ICME to Materials Design, Development, and Rapid Qualificationin 55th AIAA/ASMe/ ASCE/AHS/SC Struct Struct Dyn Mater Conf 1-7 (American Institute of Aeronautics and Astronautics, 2014).

53. Hornbogen, E. Design alloys for $>3 \mathrm{GPa}$ steelsin Innov Ultrahigh-Strength Steel Technol Sagamore Army Mater Res Conf (eds Olson G. B., Azrin M. \& Wright E. S.) 113-126 (U.S. Government Printing Office, 1990).

54. Wang, J. S., Mulholland, M. D., Olson, G. B. \& Seidman, D. N. Prediction of the yield strength of a secondary-hardening steel. Acta. Mater. 61, 4939-4952 (2013).

55. Kantner, C. D. Designing Strength, Toughness, and Hydrogen Resistance, Doctoral Thesis (Northwestern University, 2002).

56. Nabarro, F. R. N. Fifty-year study of the Peierls-Nabarro stress. Mater Sci Eng A 234-236, 67-76 (1997).

57. Nabarro, F. R. N. Dislocations in a simple cubic lattice. Proc. Phys. Soc. 59, 256 (1947).

58. Wang, J. N. A new modification of the formulation of Peierls stress. Acta. Mater. 44, 1541-1546 (1996).

59. Nembach, E. Particle Strengthening of Metals and Alloys. (John Wiley, 1997).

60. Nembach, E., Schänzer, S., Schröer, W. \& Trinckauf, K. Hardening of nickel-base superalloys by high volume fractions of $\gamma^{\prime}$-precipitates. Acta. Metall. 36, 1471-1479 (1988).

61. Huether, W. \& Reppich, B. Interaction of dislocations with coherent, stress-free, ordered particles. Zeitschrift fuer Met. Res. Adv. Tech. 69, 628-634 (1978).

62. Tiemens, B., Sachdev, A. \& Olson, G. B. Cu-precipitation strengthening in ultrahigh-strength carburizing steels. Metall. Mater. Trans. A 43, 3615-3625 (2012)

63. Tiemens, B. L., Sachdev, A. K., Mishra, R. K. \& Olson, G. B. Three-dimensional (3-D) atom probe tomography of a Cu-precipitation-strengthened, ultrahigh-strength carburized steel. Metall. Mater. Trans. A Phys. Metall. Mater. Sci. 43, 3626-3635 (2012)

64. Cowie, J. G., Azrin, M. \& Olson, G. B. Microvoid formation during shear deformation of ultrahigh strength steels. Metall. Trans. A, Phys. Metall. Mater. Sci. 20A, 143-153 (1989).

65. Lippard, H. E. et al. Microsegregation behavior during solidification and homogenization of AerMet100 steel. Metall. Mater. Trans. B Process Metall. Mater. Process. Sci. 29, 205-210 (1998).

66. Olson, G. B. Transformation plasticity and toughening. J. Phys. IV JP 6, C1-407-C1-418 (1996).

67. Haidemenopoulos, G. N., Grujicic, M., Olson, G. B. \& Cohen, M. Thermodynamicsbased alloy design criteria for austenite stabilization and transformation toughening in the Fe-Ni-Co system. J. Alloys Compd. 220, 142-147 (1995).

68. Wu, R., Freeman, A. J. \& Olson, G. B. First principles determination of the effects of phosphorus and boron on iron grain boundary cohesion. Science 265, 376-380 (1994).
69. Olson, G. B. Corrosion Resistant Steels for Structural Applications in Aircraft (Strategic Environmental Research and Development Program (SERDP), Department of Defense, 2005). Available online at: https://www.serdp-estcp.org/ content/download/6302/84489/file/PP-1224-FR-01.pdf.

70. Moskovic, R. \& Flewitt, P. E. J. An overview of the principles of modeling charpy impact energy data using statistical analyses. Metall. Mater. Trans. A 28, 2609-2623 (1997).

71. Cowie, J. G. \& Tuler, F. R. The influence of second-phase dispersions on shear instability and fracture toughness of ultrahigh strength AISI 4340 steel. Mater. Sci. Eng. A 141, 23-37 (1991).

72. Hillert, M. On the estimation of the Zener drag on grain boundaries. Scr. Metall. 18, 1431-1432 (1984).

73. Hillert, M. Inhibition of grain growth by second-phase particles. Acta. Metall. 36, 3177-3181 (1988).

74. Wörner, C. H., Cabo, A. \& Hillert, M. On the limit for particle attachment in Zener drag. Scr. Metall. 20, 829-831 (1986).

75. Hao, S., Moran, B., Kam Liu, W. \& Olson, G. B. A hierarchical multi-physics model for design of high toughness steels. J. Comput. Mater. Des. 10, 99-142 (2003).

76. Hao, S., Liu, W. K., Moran, B., Vernerey, F. \& Olson, G. B. Multi-scale constitutive model and computational framework for the design of ultra-high strength, high toughness steels. Comput. Methods Appl. Mech. Eng. 193, 1865-1908 (2004).

77. Vernerey, F. et al. The 3-D computational modeling of shear-dominated ductile failure in steel. JOM 58, 45-51 (2006).

78. Vernerey, F. J., Liu, W. K., Moran, B. \& Olson, G. B. A micromorphic model for the multiple scale failure of heterogeneous materials. J. Mech. Phys. Solids 56, 1320-1347 (2008)

79. Tian, R. et al. A multiresolution continuum simulation of the ductile fracture process. J. Mech. Phys. Solids 58, 1681-1700 (2010).

80. Zhang, S., Kontsevoi, O. Y., Freeman, A. J. \& Olson, G. B. First principles investigation of zinc-induced embrittlement in an aluminum grain boundary. Acta. Mater. 59, 6155-6167 (2011).

81. Medvedeva, N. I., Gornostyrev, Y. N., Kontsevoi, O. Y. \& Freeman, A. J. Ab-initio study of interfacial strength and misfit dislocations in eutectic composites: NiAl/ Mo. Acta. Mater. 52, 675-682 (2004).

82. Zhang, S., Kontsevoi, O. Y., Freeman, A. J. \& Olson, G. B. Cohesion enhancing effect of magnesium in aluminum grain boundary: a first-principles determination. Appl. Phys. Lett. 100, 231904 (2012).

83. Lee, J. H., Shishidou, T., Zhao, Y. J., Freeman, A. J. \& Olson, G. B. Strong interface adhesion in Fe/TiC. Philos. Mag. 85, 3683-3697 (2005).

84. Wang, J.-S. \& Olson, G. B. Prediction of ductile fracture toughness. in 12th Int. Conf. Fract. 2009, ICF-12 1, 145-154 (2009).

85. Pardoen, T. \& Hutchinson, J. W. An extended model for void growth and coalescence. J. Mech. Phys. Solids 48, 2467-2512 (2000).

86. Pardoen, T. \& Hutchinson, J. W. Micromechanics-based model for trends in toughness of ductile metals. Acta. Mater. 51, 133-148 (2003).

87. Geng, W.-T., Freeman, A. J., Olson, G. B., Tateyama, Y. \& Ohno, T. Hydrogenpromoted grain boundary embrittlement and vacancy activity in metals: Insights from ab initio total energy calculatons. Mater. Trans. 46, 756-760 (2005).

88. Zhong, L., Wu, R., Freeman, A. J. \& Olson, G. B. Charge transfer mechanism of hydrogen-induced intergranular embrittlement of iron. Phys. Rev. B 62, 13938-13941 (2000).

89. Geng, W. T., Freeman, A. J. \& Olson, G. B. Influence of alloying additions on grain boundary cohesion of transition metals: first-principles determination and its phenomenological extension. Phys. Rev. B 63, 165415 (2001).

90. Wu, R., Freeman, A. J. \& Olson, G. B. On the electronic basis of the phosphorus intergranular embrittlement of iron. J. Mater. Res. 7, 2403-2411 (1992).

91. Wu, R., Freeman, A. J. \& Olson, G. B. Effects of carbon on Fe-grain-boundary cohesion: first-principles determination. Phys. Rev. B 53, 7504-7509 (1996).

92. Rice, J. R. \& Wang, J.-S. Embrittlement of interfaces by solute segregation. Mater. Sci. Eng. A 107, 23-40 (1989).

93. Olson, G. B., Cohen, M. Martensitic transformations as a deformation processin Mechanical properties and phase transformations in engineering materials-Earl $R$ Parker Symposium on Structure Property Relationships (eds Antolovich S. D., Ritchie R. O. \& Gerberich W. W.) 367-390 (The Metallurgical Society, Inc., 1986).

94. Olson, G. B., Feinberg, Z. D. in Phase Transform Steels Fundam Diffus Control Transform Vol 2 (eds Arnold S. \& Pereloma E.) 59-82 (Woodhead Publishing Ltd., 2012).

95. Leal, R. H. Transformation Toughening of Metastable Austenitic Steels, Doctoral Thesis (Massachusetts Institute of Technology, 1984).

96. Stavehaug, F. Transformation Toughening of gamma-strengthened Metastable Austenitic Steels, Doctoral Thesis Massachusetts Institute of Technology, (1990).

97. Ghosh, G. \& Olson, G. B. Kinetics of f.c.c. $\rightarrow$ b.c.c. heterogeneous martensitic nucleation-I. The critical driving force for athermal nucleation. Acta. Metall. Mater. 42, 3361-3370 (1994) 
98. Ghosh, G. \& Olson, G. B. Kinetics of F.c.c. $\rightarrow$ b.c.c. heterogeneous martensitic nucleation-II. Thermal activation. Acta. Metall. Mater. 42, 3371-3379 (1994).

99. Olson, G. B. \& Cohen, M. A general mechanism of martensitic nucleation: Part I. General concepts and the FCC $\rightarrow \mathrm{HCP}$ transformation. Metall. Trans. A 7, 1897-1904 (1976).

100. Olson, G. B. \& Cohen, M. A general mechanism of martensitic nucleation: Part II. $\mathrm{FCC} \rightarrow \mathrm{BCC}$ and other martensitic transformations. Metall. Trans. A 7, 1905-1914 (1976).

101. Olson, G. B., Cohen, M. in Dislocations Solids (ed. Nabarro F. R. N.) (Elsevier Science B.V., 1986).

102. Dyson, B. F. Microstructure based creep constitutive model for precipitation strengthened alloys: theory and application. Mater. Sci. Technol. 25, 213-220 (2009).

103. Zhu, Z., Basoalto, H., Warnken, N. \& Reed, R. C. A model for the creep deformation behaviour of nickel-based single crystal superalloys. Acta. Mater. 60, 4888-4900 (2012).

104. Socrate, S. \& Parks, D. M. Numerical determination of the elastic driving force for directional coarsening in Ni-superalloys. Acta. Metall. Mater. 41, 2185-2209 (1993).

105. Jung, J., Ghosh, G. \& Olson, G. B. A comparative study of precipitation behavior of Heusler phase (Ni2TiAl) from B2-TiNi in Ni-Ti-Al and Ni-Ti-Al-X (X=Hf, Pd, Pt, Zr) alloys. Acta. Mater. 51, 6341-6357 (2003)

106. Lu, X.-G., Selleby, M. \& Sundman, B. Theoretical modeling of molar volume and thermal expansion. Acta. Mater. 53, 2259-2272 (2005).

107. Lu, X.-G., Selleby, M. \& Sundman, B. Assessments of molar volume and thermal expansion for selected bcc, fcc and hcp metallic elements. CALPHAD 29 , 68-89 (2005).

108. Pineau, A., McDowell, D. L., Busso, E. P. \& Antolovich, S. D. Failure of metals II: Fatigue. Acta. Mater. http://dx.doi.org/10.1016/j.actamat.2015.05.050 (in press).

109. Sornette, D., Magnin, T. \& Brechet, Y. The physical origin of the Coffin-Manson law in low-cycle fatigue. Europhys. Lett. 20, 433 (1992).

110. Moore, J. A. A Micromechanics-Based Method for Multiscale Fatigue Prediction (Doctoral Thesis Massachusetts Institute of Technology, 2015).
111. Frankel, D. J. Design of Fatigue Resistant Heusler-strengthened PdTi-based Shape Memory Alloys for Biomedical Applications (Doctoral Thesis, Massachusetts Institute of Technology, 2015).

112. Frankel, D. \& Olson, G. Design of Heusler precipitation strengthened NiTi- and PdTi-Base SMAs for cyclic performance. Shape Mem. Superelasticity 1, 162-179 (2015).

113. Jou, H.-J., Voorhees, P. W. \& Olson, G. B. Computer simulations for the prediction of microstructure/property variation in aeroturbine disks. in Superalloys (eds Green, K. A. et al.) 877-886 (2004).

114. Zhao, J.-C., Jackson, M. R., Peluso, L. A. \& Brewer, L. N. A diffusion multiple approach for the accelerated design of structural materials. MRS Bull. 27, 324-329 (2002).

115. Palumbo, M. et al. Thermodynamic modelling of crystalline unary phases. Phys. Status Solidi. 251, 14-32 (2014)

116. Xiong, W., Selleby, M., Chen, Q., Odqvist, J. \& Du, Y. Phase equilibria and thermodynamic properties in the Fe-Cr System. Crit. Rev. Solid State Mater. Sci. 35, 125-152 (2010).

117. Squires, D. R. \& Wilson, E. A. Effect of cobalt on impact toughness of steels. Mater. Sci. Technol. 10, 52-55 (1994).

118. Shibayama, T., Yamagata, I., Kayano, H. \& Namba, C. Effect of small additional elements on DBTT of $\mathrm{V}-4 \mathrm{Cr}-4 \mathrm{Ti}$ irradiated at low temperatures. J. Nucl. Mater. 258-263, 1361-1368 (1998).

119. McDowell, D. L. \& Olson, G. B. Concurrent design of hierarchical materials and structures. Sci. Model. Simul. SMNS 15, 207-240 (2008).

This work is licensed under a Creative Commons Attribution 4.0 International License. The images or other third party material in this article are included in the article's Creative Commons license, unless indicated otherwise in the credit line; if the material is not included under the Creative Commons license, users will need to obtain permission from the license holder to reproduce the material. To view a copy of this license, visit http://creativecommons.org/licenses/ by/4.0/ 